\title{
Molecular-Genetic Imaging Based on Reporter Gene Expression
}

\author{
Joo Hyun Kang ${ }^{1,2}$ and June-Key Chung ${ }^{1}$ \\ ${ }^{1}$ Department of Nuclear Medicine, Cancer Research Institute, Tumor Immunity Medical Research Center, College of Medicine, \\ Seoul National University, Seoul, Korea; and ${ }^{2}$ Laboratory of Nuclear Medicine, Korea Institute of Radiological and Medical Science, \\ Seoul, Korea
}

\begin{abstract}
Molecular imaging includes proteomic, metabolic, cellular biologic process, and genetic imaging. In a narrow sense, molecular imaging means genetic imaging and can be called moleculargenetic imaging. Imaging reporter genes play a leading role in molecular-genetic imaging. There are 3 major methods of molecular-genetic imaging, based on optical, MRI, and nuclear medicine modalities. For each of these modalities, various reporter genes and probes have been developed, and these have resulted in successful transitions from bench to bedside applications. Each of these imaging modalities has its unique advantages and disadvantages. Fluorescent and bioluminescent optical imaging modalities are simple, less expensive, more convenient, and more user friendly than other imaging modalities. Another advantage, especially of bioluminescence imaging, is its ability to detect low levels of gene expression. MRI has the advantage of high spatial resolution, whereas nuclear medicine methods are highly sensitive and allow data from small-animal imaging studies to be translated to clinical practice. Moreover, multimodality imaging reporter genes will allow us to choose the imaging technologies that are most appropriate for the biologic problem at hand and facilitate the clinical application of reporter gene technologies. Reporter genes can be used to visualize the levels of expression of particular exogenous and endogenous genes and several intracellular biologic phenomena, including specific signal transduction pathways, nuclear receptor activities, and protein-protein interactions. This technique provides a straightforward means of monitoring tumor mass and can visualize the in vivo distributions of target cells, such as immune cells and stem cells. Molecular imaging has gradually evolved into an important tool for drug discovery and development, and transgenic mice with an imaging reporter gene can be useful during drug and stem cell therapy development. Moreover, instrumentation improvements, the identification of novel targets and genes, and imaging probe developments suggest that molecular-genetic imaging is likely to play an increasingly important role in the diagnosis and therapy of cancer.
\end{abstract}

\footnotetext{
Received Aug. 23, 2007; revision accepted Apr. 9, 2008.

For correspondence or reprints contact: June-Key Chung, Department of Nuclear Medicine, Seoul National University Hospital, 28, Yongon-dong, Jongno-gu, Seoul 110-744, Korea.

E-mail: jkchung@plaza.snu.ac.kr

COPYRIGHT @ 2008 by the Society of Nuclear Medicine, Inc.
}

Key Words: molecular-genetic imaging; reporter gene; optical image; MRI; PET

J Nucl Med 2008; 49:164S-179S

DOI: 10.2967/jnumed.107.045955

$\mathbf{M}$ olecular imaging allows the visualization of normal and abnormal cellular processes in living subjects at the molecular or genomic level rather than at the anatomic level (1). Molecular imaging is a new biomedical discipline that enables the visualization, characterization, and quantification of biologic processes at the cellular and subcellular levels within living subjects. Moreover, molecular and genetic changes precede anatomic changes during disease development, and thus, molecular-genetic imaging can detect events that occur during the initial stages of disease progression, including carcinogenesis. Conventional imaging such as radiography, ultrasonography (US), CT, and MRI can visualize anatomic morphologic changes. SPECT and functional MRI or PET using radiolabeled metabolic substances, including glucose, amino acids, or nucleotides, can visualize functional physiologic changes or biochemical changes. The original genetic problems in the beginning of disease could be monitored by molecular-genetic imaging (Fig. 1).

Molecular imaging, a combination of molecular biology and medical imaging, is rapidly growing and combines the disciplines of cell biology, molecular biology, chemistry, pharmacology, genetics, biomedical physics, engineering, and medicine. Molecular imaging includes proteomic, metabolic, cellular biologic processes, and genetic imaging. In a narrow sense, molecular imaging means genetic imaging, or the so-called molecular-genetic imaging, and currently, 2 types of molecular-genetic imaging are available based on reporter genes and labeled antisense oligonucleotide probes.

The levels of expression of a therapeutic gene can be evaluated by assaying reporter gene expression in the conventional manner. Initially, a recombinant plasmid simultaneously expressing therapeutic and reporter genes is constructed and then transfected into target cells. Thus, transcription and translation of therapeutic and reporter genes occur simultaneously, and by assaying reporter protein activity, the expression of the therapeutic gene can be deduced. Conventional assays of 


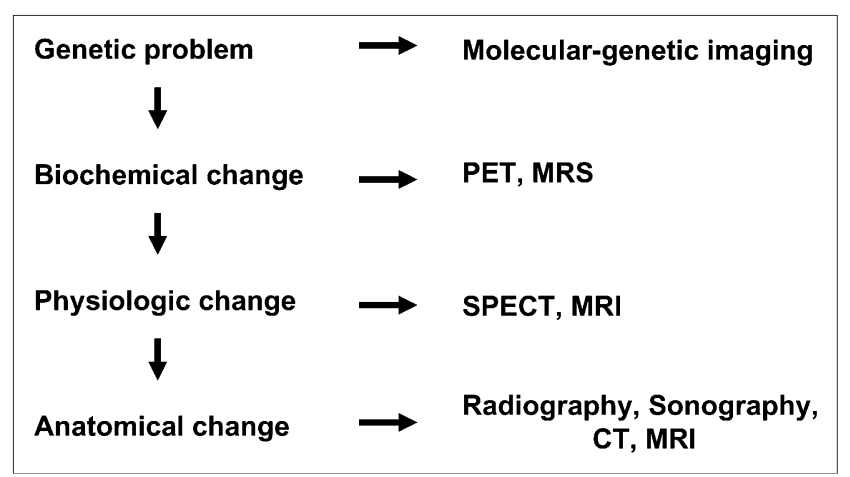

FIGURE 1. Schematic explanation of disease progression and development of imaging modality. In many diseases, including cancer, genetic problem occurs first and then is followed by biochemical, functional, and morphologic changes. Conventional images can visualize anatomic morphologic change. SPECT, $\mathrm{MRI}$, and PET can visualize functional physiologic change and biochemical change. Molecular-genetic imaging has been designed to visualize original genetic problem. MRS $=\mathrm{MR}$ spectroscopy.

reporter gene expression involve $\beta$-galactosidase, alkaline phosphatase, luciferase, and green fluorescent protein (GFP), but measurements of the levels of expression of these reporter proteins (enzymes) usually require tissue samples; therefore, noninvasive techniques capable of repetition are required to determine transgene expression in living animals. The new reporter proteins in cells transfected with an imaging reporter gene induce the accumulation of specific imaging signals that allow the location, duration, and magnitude of transgene expression to be visualized. Thus, measurements of specific imaging signals provide indirect information that reflects the level of reporter gene expression $(2,3)$.

Radiolabeled antisense oligonucleotide probes have been used to directly image endogenous gene expression at the transcription level. Sequences of radiolabeled antisense oligonucleotide that are complementary to small segments of target mRNA or DNA sequences can be synthesized (4), and $\gamma$-camera and PET of endogenous gene expression using radiolabeled antisense oligonucleotides have been reported $(5,6)$. However, conclusive demonstrations of this technique have been hindered by formidable biologic barriers and by low concentrations of target mRNA or DNA (7). Thus, in this review, we will mainly focus on imaging reporter genes.

\section{REPORTER GENE IMAGING MODALITIES}

There are 3 major means of molecular imaging based on optical, MRI, and nuclear medicine modalities (Table 1) $(4,8)$. In the fields of diagnostic radiology, CT and US have been examined as means of molecular-genetic imaging, but these techniques remain in the early developmental stages.

\section{Optical Imaging}

Instrument Considerations. Fluorescent protein and luciferase have been used as reporter genes in the biochemical and molecular biologic fields and have sensitivities that are com-
TABLE 1

Applicable Reporter Genes

\begin{tabular}{|c|c|c|}
\hline Modality & Reporter & Reference(s) \\
\hline \multirow[t]{2}{*}{$\begin{array}{l}\text { Optical reporter } \\
\text { genes }\end{array}$} & $\begin{array}{l}\text { Fluorescent protein } \\
\text { (red, green) }\end{array}$ & 17,18 \\
\hline & $\begin{array}{l}\text { Luciferase (firefly, } \\
\text { click beetle, renilla, } \\
\text { gaussia) }\end{array}$ & $9,14-16$ \\
\hline \multirow{7}{*}{$\begin{array}{c}\text { Nuclear medicine } \\
\text { reporter genes }\end{array}$} & HSV1 TK & $2,3,62,63$ \\
\hline & $\begin{array}{l}\text { Human mitochondrial } \\
\text { TK }\end{array}$ & 33 \\
\hline & $\mathrm{D}_{2} \mathrm{R}$ & 34,35 \\
\hline & NIS & $41-43$ \\
\hline & $\begin{array}{l}\text { Norepinephrine } \\
\text { transporter }\end{array}$ & 40,44 \\
\hline & SSTr & 39 \\
\hline & Estrogen receptor & 36 \\
\hline \multirow{5}{*}{$\begin{array}{l}\text { MRI reporter } \\
\text { genes }\end{array}$} & Transferrin receptor & 22 \\
\hline & $\beta$-galactosidase & 23 \\
\hline & Tyrosinase & 24,25 \\
\hline & Ferritin & 26,27 \\
\hline & LRP & 28 \\
\hline
\end{tabular}

parable to those of other reporters, such as $\beta$-galactosidase and chloramphenicol acetyltransferase (9). The acquisition of the images of small animals expressing fluorescent proteins or luciferase might be possible using recently developed in vivo imaging systems equipped with a cooled chargecoupled device (CCD) camera (10). Cooled CCD cameras generate lower levels of thermal noise, which increases signal-to-noise ratio while preserving spectral sensitivity. These systems are sensitive to light across the entire visible spectrum and into the near-infrared (4). CCD cameras used for the in vivo imaging of living, anesthetized mice are mounted within a light-tight chamber. Conventional pictures of mice can be obtained after a brief light flash within the chamber, and fusion images of optical and real photographic pictures can be made (11).

Fluorescence imaging uses a fluorophore (fluorescent protein) that is excited by an external light source with a wavelength a little shorter than that of the emitted light. Suitable optical filters are used to select excitation and emission wavelengths during fluorescent imaging, but are only applied to emitted light for bioluminescent imaging (12). Recently, a novel system enabling 3-dimensional imaging of fluorescent probes in whole animals was developed in parallel with a 3-dimensional surface reconstruction algorithm (13).

Genes and Probes. Because of the sensitivity of liquidcooled CCD cameras and the low background level of visible light emitted from tissues, bioluminescent imaging has great sensitivity. Moreover, images can be obtained within minutes of administering nontoxic substrate solution intravenously or intraperitoneally. Substrates required for bioluminescent imaging are commercially available and have long shelf lives (11). 
Luciferase from the firefly Photinus pyralis (Fluc) has been most widely used as a bioluminescence reporter gene. When Fluc acts on luciferin, in the presence of adenosine triphosphate (ATP), magnesium, and oxygen, it catalyzes the conversion of luciferin to oxyluciferin and simultaneously produces $\mathrm{CO}_{2}$, phosphate, and light. During this reaction, luciferase converts chemical energy into photons, in a process that does not require external light. In the case of Fluc, a portion of this chemical energy is released as visible light (blue to yellow-green in color) with an emission spectrum (490- to 620-nm wavelengths) that peaks at $560 \mathrm{~nm}$ (4). The click beetle luciferase using ATP, oxygen, and a common luciferin as substrate was identified from Pyrophorus plagiophthalamus (14). Four types of beetle luciferase are distinguishable by their abilities to emit different colors of bioluminescence ranging from green $(546 \mathrm{~nm})$ to orange $(593 \mathrm{~nm})$ and the characteristics of these beetle luciferases may be applicable to experiments in which multiple reporters are simultaneously needed. The renilla luciferase (Rluc) and gaussia luciferase (Gluc) genes were, respectively, cloned from Renilla reniformis, the sea pansy, and Gaussia princeps, the marine copepod. They both use coelenterazine as a substrate, which is converted to coelenteramide, $\mathrm{CO}_{2}$, and light. In contrast to Fluc, Rluc does not require ATP to metabolize coelenterazine $(15,16)$.

GFP has been used for over a decade to visualize subcellular compartments or to track specific molecules within cells. In vitro, fluorescent protein indicators can be designed to track the distribution and localization of specific proteins or to visualize the responses of cells and tissues to biologic events (17). Five different fluorescent proteins with emission spectra peaks in the 450- to 650-nm region have been applied to in vivo imaging. Moreover, the unique emission wavelengths of these fluorescent proteins make it possible to simultaneously image multiple targets of interest in cells and tissue (18).

However, animal fluorescence imaging is hampered by low signal-to-background ratios and autofluorescence (19). Much research has targeted eliminating these disadvantages via the development of new fluorescent proteins with long emission of near-infrared wavelengths $(700-900 \mathrm{~nm})$, which have lower tissue absorption coefficients (20). Several other useful variants have been isolated from different organisms to generate genetically modified fluorescent proteins.

\section{MRI}

Instrument Considerations. The MRI method converts relaxation time differences to image contrast differences. Recently micro-MRI units with high tesla values were developed for high-resolution small-animal imaging. However, MRI has not been used extensively for reporter gene imaging.

Genes. Gilad et al. (21) classified MRI approaches on the basis of interactions at the molecular level: the expression of surface receptors that enable the binding of specific MRI contrast agents; the enzyme-based cleavage of functional groups that block water (proton) exchange, protein binding, or MRI contrast agents; and the expression of para- and antiferromagnetic proteins involved with iron metabolism, such as tyrosinase and ferritin.

Iron enters cells through transferrin receptor (TfR), which binds transferrin (Tf) protein. After binding iron-loaded transferrin molecules to TfR, it internalizes rapidly. The TfR-Tf complex then dissociates in acidic cytoplasmic endosomes, and the iron is released, which decreases T2 signals. TfR can be highly expressed on the cell membrane after transfer of its gene as a reporter gene to target cells (22). Ultra small superparamagnetic iron oxides have been successfully used as imaging probes.

Louie et al. (23) used $\beta$-galactosidase as an MRI reporter gene using gadolinium chelated by galactose. When the chelate is intact, the $\mathrm{Gd}^{3+}$ contrast agent is shielded from tissue water. However, in the presence of galactosidase, the galactose units are cleaved and the contrast agents are released, which cause in inner sphere relaxation enhancement and increase contrast. As a reporter gene, $\beta$-galactosidase has an advantage of a low background level.

Iron binding metalloproteins such as tyrosinase and ferritin have also been suggested as MRI reporter genes. Tyrosinase plays a role in melanin biosynthesis, and melanin has a high affinity for iron, as evidenced by ironinduced T1 hyperintensities. Changes in the MRI signals of tyrosinase-expressing cells have been detected in vitro $(24,25)$. Ferritin is another metalloprotein that serves as an iron reservoir in vivo, and a rat glioma xenograft expressing the ferritin gene under the control of an inducible tetracycline promoter was found to clearly exhibit reduced $\mathrm{T} 1$ and $\mathrm{T} 2$ (26). Genove et al. (27) also reported ferritin gene as an MRI reporter using replication-defective adenoviral vector to deliver the ferritin transgene. Recently, nonmetallic, biodegradable artificial MRI reporter gene encoding lysine-rich protein (LRP) was developed (28). This agent based on rapid transfer of amide proton in LRP to water proton can produce chemical-exchange saturation transfer contrast in solution, reducing MRI signal intensity. The signal intensity change for an LRP-expressing xenograft was quite different from that for a control xenograft in the brains of nonobese mice with diabetes or severe combined immunodeficiency, confirming LRP as a potential MRI reporter to track cells.

\section{Nuclear Medicine Imaging}

Instrument Considerations. Recently, several small-animal PET high-resolution cameras were developed. Current smallanimal PET scanners have a spatial resolution of $\sim 2 \mathrm{~mm}^{3}(29)$. Small-animal dedicated SPECT systems with pinhole collimators also have been developed and have higher resolutions than PET units. Rapid advances in imaging technologies have now resulted in the development of fused imaging modalities, such as PET/CT, SPECT/CT, and PET/MRI $(30,31)$. These fusion machines provide the colocalization of biologic and precise anatomic information.

Genes and Probes. Initially, imaging reporter genes were investigated in combination with high-resolution PET. Current PET reporter gene paradigms fall into 2 categories, that 
is, enzyme based (herpes simplex virus type 1 [HSV1] thymidine kinase (TK) gene [HSV1-tk]) and receptor based (dopaminergic receptor gene) (Fig. 2) (2,3,32).

The HSV1-tk gene is the more commonly used of the 2 genes. In HSV1-tk-transfected cells, the HSV1-tk gene is transcribed to HSV1-tk mRNA and translated to TK, which then phosphorylates its substrate, for example, ${ }^{124}$ I-FIAU. Whereas unphosphorylated ${ }^{124}$ I-FIAU can traverse the cell membrane, phosphorylated ${ }^{124}$ I-FIAU cannot, and thus remains trapped within cells, which emit positrons that allow its visualization by PET. Thus, PET images can localize HSV1-tk gene expression and reflect the magnitude of reporter probe accumulation. Moreover, radioactivity levels in transduced cells reflect TK activity and levels of HSV1-tk gene expression. TK has 2 substrate types, ${ }^{18} \mathrm{~F}$ - or ${ }^{124} \mathrm{I}$-labeled thymidine derivatives, such as ${ }^{124}$ I-FIAU and ${ }^{124}$ I-FEAU, and acycloguanosine derivatives, such as ganciclovir and 9-[4$\left[{ }^{18} \mathrm{~F}\right]$ fluoro-3-(hydroxymethyl)butyl $]$ guanine $\left({ }^{18} \mathrm{~F}-\mathrm{FHBG}\right)(2,3)$.

A mutant HSV1 TK (HSV1-sr39tk gene), a mutant enzyme with 5 amino acid substitutions, was constructed to reduce the TK detection limit (32). This mutant TK uses more effectively fluorinated acycloguanosines as substrates and, consequently, is a more effective PET reporter gene. The HSV1-sr39tk gene- ${ }^{18} \mathrm{~F}-\mathrm{FHBG}$ combination is currently the most effective PET system (11). To avoid immunogenicity of nonhuman derived reporter protein, the human mitochondrial TK type 2 (hTK2) was developed as nuclear imaging reporter. Small-animal PET of retrovirus-transduced expression of truncated hTK2 in tumor xenografts was clearly visualized using ${ }^{124}$ I-FIAU and ${ }^{18}$ F-FEAU. However, ${ }^{18} \mathrm{~F}-\mathrm{FHBG}$ accumulation in tumors expressing a truncated hTK2 reporter gene was low (33).
The dopamine 2 receptor $\left(\mathrm{D}_{2} \mathrm{R}\right)$ gene is also used as an imaging reporter gene, because of the availability of the wellestablished radiolabeled probe ${ }^{18} \mathrm{~F}$-fluoroethylspiperone (FESP) (34). PET signals from ${ }^{18} \mathrm{~F}$-FESP in $\mathrm{D}_{2} \mathrm{R}$-expressing cells correlate well with tritium-labeled spiperone binding and $\mathrm{D}_{2} \mathrm{R}$ gene expression. Quantitative in vivo assays of ${ }^{18} \mathrm{~F}$ FESP accumulation and in vitro assays of hepatic $D_{2} R$ levels demonstrated that noninvasive small-animal PET analysis of accumulated radioactivity in target tissues accurately reflects gene expression levels (11). Kummer et al. (35) simultaneously expressed HSV1-sr39tk and $\mathrm{D}_{2} \mathrm{R} 80 \mathrm{~A}$ in a human glioma model by universal HSV1 amplicon vector with bicistronic cassette and confirmed gene expression by quantitative colocalization in PET signals of 2 reporters.

Estrogen receptor is also used as a PET gene. Furukawa et al. (36) designed a new reporter gene imaging system based on ${ }^{18} \mathrm{~F}$-labeled estradiol and human estrogen receptor ligand (hERL) binding domain. This system has the advantages that ${ }^{18} \mathrm{~F}$-labeled estradiol is used in human studies, that it accesses a wide range of tissues, and that hERL lacking DNA binding domain can no longer work as a transcription factor. They performed basic studies to evaluate its potential for gene therapy monitoring.

However, conventional PET reporter genes require the synthesis of complicated substrates and an expensive PET unit. Thus, several investigators have investigated the use of $\gamma$-emitters for molecular imaging $(37,38)$; examples include the somatostatin receptor (SSTr) 2 (SSTr2) gene and ${ }^{111} \mathrm{In}$ octreotide (39), the norepinephrine transporter gene and ${ }^{131}$ I-labeled metaiodobenzylguanidine ( ${ }^{131} \mathrm{I}-\mathrm{MIBG}$ ) (40), and the sodium/iodide symporter (NIS) gene and radioiodines or ${ }^{99 \mathrm{~m}} \mathrm{Tc}$-pertechnetate (41-43).

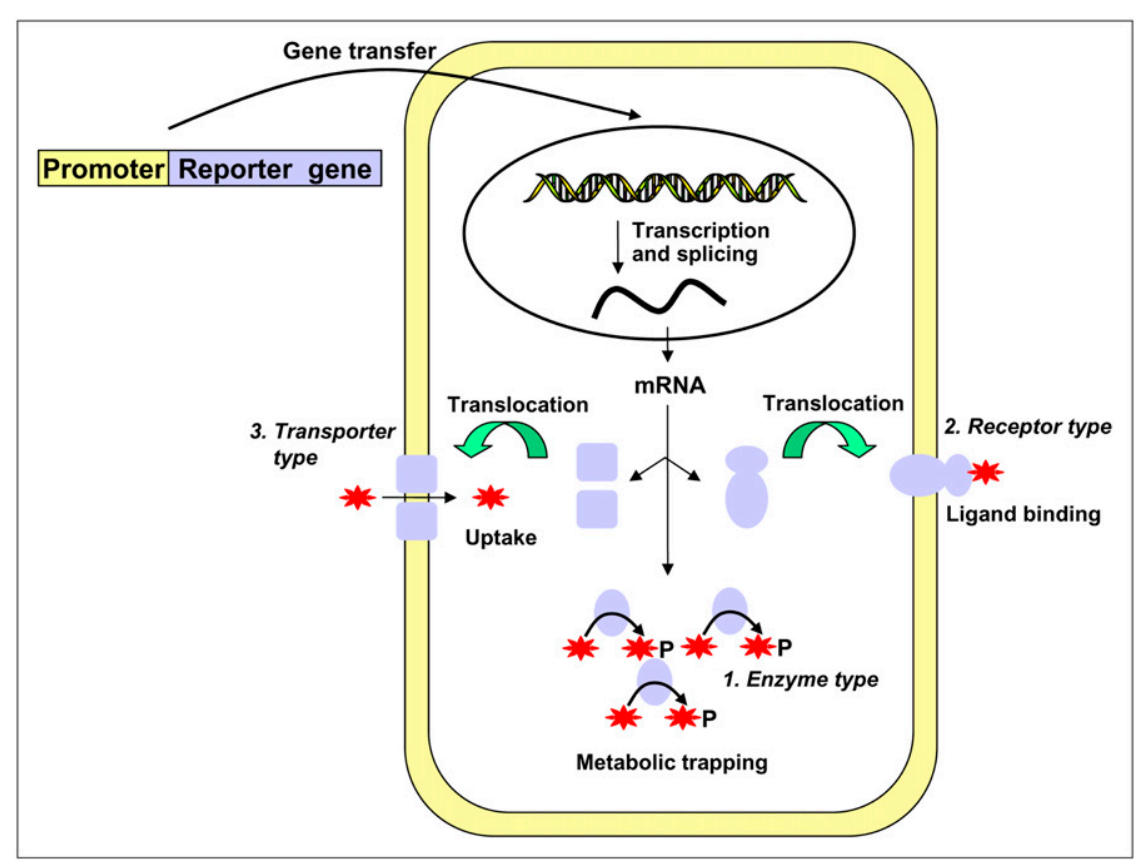

FIGURE 2. Schematic illustration of 3 types of reporter gene expression used in nuclear medicine modality. Representatives of enzyme type and transporter type are HSV1-tk (ovals) and NIS (squares), respectively. Receptor types are $D_{2} R$, norepinephrine receptor, and SSTr2. Stars represent radioisotope-labeled substrates (enzyme) or ligands (receptor) or radionuclide itself (transporter type). 
SSTrs are G-protein-linked 7-membrane pass receptors. Moreover, the expression of SSTr2, 1 of the 6 SSTr genes, is essentially restricted to the pituitary, though other tissues express lower levels of SSTr2, which reduces background activity. However, ligand binding to SSTr2 reporter gene can alter target cell physiology (39).

Human norepinephrine transporter (hNET) can be used as an imaging reporter gene because of the availability of radioiodinated MIBG and ${ }^{11} \mathrm{C}$-ephedrine as imaging probes. In vivo experiments performed on nude mice bearing both hNET-expressing and wild-type tumors showed a 10-foldhigher accumulation of ${ }^{131}$ I-MIBG in hNET-transfected tumors (40). Recently, Moroz et al. developed retroviral vector system expressing GFP and hNET and generated several reporter gene-expressing cell lines (44). Imaging studies using reporter gene-expressing C6 xenografts suggested several advantages of ${ }^{124}$ I-MIBG PET images over ${ }^{123}$ I-MIBG $\gamma$-camera or SPECT images. This result was primarily due to the longer half-life of ${ }^{124} \mathrm{I}$, to retention and slow clearance of ${ }^{123}$ I-MIBG, and to higher resolution of PET.

Of the previously described gene systems, the NIS gene system is probably the simplest and most easily applied. Other groups and our own have demonstrated that the NIS gene serves as an alternative imaging reporter gene (4143). Iodide enters thyroid cells with sodium via a specific transporter; the so-called sodium/iodide symporter. Transmembrane concentration gradients of sodium ion provide the driving force for iodide uptake, and these gradients are generated and maintained by the sodium-potassium pump (ATPase).

The rat NIS gene was identified in 1996 (45), and the human NIS (hNIS) gene was isolated and cloned using a complementary DNA sequence of rat NIS (46). The hNIS gene contains 15 exons interrupted by 14 introns and codes for a 3.9-kilobase mRNA transcript. NIS is an intrinsic membrane protein with 13 putative transmembrane domains, an extracellular amino-terminal domain and an intracellular carboxy-terminal domain (47). NIS cotransports 2 sodium ions and 1 iodide ion. In addition to iodide, several other anions are transported by NIS, that is, $\mathrm{ClO}_{4}{ }^{-}>\mathrm{ReO}_{4}{ }^{-}$ $>\mathrm{I}^{-} \geq \mathrm{SCN}^{-}>\mathrm{ClO}_{3}{ }^{-}>\mathrm{NO}_{3}{ }^{-}$(48). Thus, the expression of functional NIS protein by target cells enables them to concentrate radioiodide from plasma. As might be expected, the discoveries that ${ }^{99 \mathrm{~m}} \mathrm{Tc}$-pertechnetate and ${ }^{188} \mathrm{Re}$-perrhenate also use this transporter were of importance in the nuclear imaging and radionuclide therapy.

NIS has many advantages as an imaging reporter gene due to the wide availability of its substrates, that is, radioiodines and ${ }^{99 \mathrm{~m}} \mathrm{Tc}$, and their well-understood metabolisms and clearance mechanisms. Moreover, radioiodines and ${ }^{99 \mathrm{~m}} \mathrm{Tc}$ have no labeling stability problem, whereas this is a major concern for radiolabeled compounds of $\mathrm{D}_{2} \mathrm{R}$ and HSV1-tk. In addition, NIS is unlikely to interact with the underlying cell biochemistry, and iodide is not metabolized in most tissues. Although sodium influx may be a concern, no effects have been observed to date. Thus, reporter gene imaging with NIS is more straightforward, because all nuclear medicine departments have access to a $\gamma$-camera, radioiodines, and ${ }^{99 \mathrm{~m}} \mathrm{Tc}(42)$.

\section{ADVANTAGES AND DISADVANTAGES OF DIFFERENT IMAGING MODALITIES}

\section{Optical Imaging}

Fluorescent and bioluminescent imaging studies are simpler, cheaper, more convenient, and more user friendly than other imaging modalities. Another advantage, especially for bioluminescence imaging, is their high sensitivity to detect low levels of gene expression, due to the absence of background light emission caused by external illumination. Moreover, biologic hypotheses can be tested rapidly in living experimental models, because these methods have been widely used in many in vitro reporter gene assays (11). Biologic information regarding fluorescent protein expression from in vitro cell systems also easily translated to in vivo whole-body systems, such as movement of specific cells, monitoring promoter activity, or several cellular factors. In addition, optical imaging modalities are suitable for high-throughput screening due to ease of operation, short acquisition times (usually 10-60 s), and the capability for simultaneous measurement (Table 2).

However, the attenuation of light photons is the main problem of optical imaging. About $90 \%$ of bioluminescence signal flux is lost per centimeter of tissue, and thus, photon intensities detected by CCD cameras may not proportionately or sufficiently reflect endogenous reporter gene expression in the inner organs of even small animals. Since red light better penetrates tissue, efforts are being made to generate imaging reporters that emit photons at wavelengths above $600 \mathrm{~nm}$. In particular, genetically modified mutants of GFP and luciferase have been constructed to shift emissions toward the infrared (49).

Unlike bioluminescent imaging, fluorescing proteins must be excited by an external light source, and therefore, considerations of tissue scattering and absorption by endogenous fluorochromes are doubled. Autofluorescence is another problem and limits the use of GFP.

Inability to produce 3-dimensional and tomographic images is also problematic, although some progress has been made recently $(13,50)$. In addition, because imaging reporter enzymes, such as GFP and firefly luciferase, are foreign antigens, the induction of immune responses by reporter gene expression requires certain conditions $(51,52)$. However, despite these limitations, optical molecular imaging continues to play a key role by allowing efficient, noninvasive, and rapid assessments of transgene expression in preclinical models (4).

\section{MRI}

MRI has 2 obvious advantages: high spatial resolution (micrometers) and the ability to extract physiologic and anatomic information simultaneously. However, MRI has poor sensitivity in terms of imaging enhancement agents 
TABLE 2

Comparison of Nuclear and Optical Imaging Modalities

\begin{tabular}{|c|c|c|}
\hline \multirow[b]{2}{*}{ Parameter } & \multicolumn{2}{|c|}{ Value for: } \\
\hline & Optical imaging & Nuclear medicine imaging \\
\hline Spatial resolution & $3-5 \mathrm{~mm}$ & $1-2 \mathrm{~mm}$ \\
\hline Temporal resolution & Seconds to minutes & $10 \mathrm{~s}$ to minutes \\
\hline 3-dimensional tomography & Not yet available & Yes \\
\hline Tissue penetration & $1 \mathrm{~cm}$ (variable) & No limit \\
\hline \multirow[t]{2}{*}{ Sensitivity } & $10^{-15}-10^{-17} \mathrm{~mol} / \mathrm{L}$ (bioluminescence) & $10^{-10}-10^{-12} \mathrm{~mol} / \mathrm{L}$ \\
\hline & $10^{-9}-10^{-12} \mathrm{~mol} / \mathrm{L}$ (fluorescence) & \\
\hline \multirow[t]{2}{*}{ Background } & Low (bioluminescence) & Moderate to high \\
\hline & Moderate (fluorescence) & \\
\hline Reporter gene transfer & Yes & Yes \\
\hline \multirow[t]{2}{*}{ Probes } & Yes (bioluminescence) & Radiolabeled tracers \\
\hline & No (fluorescence) & \\
\hline Chemical synthesis or labeling labor & No & Yes \\
\hline Radiation hazard & No & Yes \\
\hline \multirow[t]{2}{*}{ Costs } & Low & Low ( $\gamma$-camera) \\
\hline & & High (PET) \\
\hline Potential for clinical uses & Very low & Yes \\
\hline
\end{tabular}

and molecular reactions, requires highly trained personnel, and has high associated capital costs (53).

Moreover, despite continued efforts to develop suitable MRI reporter genes for over a decade, the field is still in its early stage (21). This lack of progress is a reflection of the pitfalls encountered due to low detection sensitivities, the undesirable pharmacokinetics of substrates, or difficulties associated with the interpretations of signal changes. To speed up developing MRI reporter genes, multimodal systems might be helpful. The multimodal systems combine bioluminescent, PET, and fluorescent imaging reporter genes with MRI reporter gene. The images of MRI reporter gene expression with high resolution may be perfectly complementary to PET or optical images with high sensitivity.

\section{Nuclear Medicine Imaging}

Nuclear imaging strategies have several advantages. They are highly sensitive and can detect at the $10^{-12} \mathrm{~mol} / \mathrm{L}$ radiotracer level, and they are highly quantitative, which means that dynamic and kinetic modeling studies can be easily performed. Moreover, although optical imaging presents attenuation problems, nuclear medicine imaging has no such problems; the latter property results in easy translation to human subjects. In addition, a broad range of molecular imaging agents has already been approved for clinical use and many novel agents are undergoing preclinical testing (Table 2) (4). This ability to translate data from small-animal PET studies to patients is of great benefit. Moreover, rapid advances in imaging technology have now resulted in the development of fused imaging modalities, such as PET/CT, SPECT/CT, and PET/MRI.

\section{Multimodality Imaging}

Because each of the aforementioned imaging technologies has unique advantages and disadvantages, researchers have developed genes, vehicles, probes, and detectors that are compatible with different imaging modalities. The development of multimodality noninvasive imaging reporter genes will allow us to choose appropriate imaging technologies to meet the demands of specific molecular biologic problems. Moreover, the clinical application of imaging reporter gene technologies is also likely to be facilitated by the use of multimodality reporter genes (11).

Several strategies based on the combined expression of multiple genes have been reported. The bicistronic approach for linking 2 genes involves the incorporation of an internal ribosomal entry site sequence between the 2 genes. Both genes are then transcribed into a single mRNA and translated into 2 different proteins. The second strategy uses fusion gene vectors, whereby the 2 genes are connected in such a way that their coding sequences are in the same reading frame. The third strategy uses bidirectional transcription, as was used to coexpress the HSV1-sr39tk and $\mathrm{D}_{2} \mathrm{R}$ genes in a bidirectional manner with centrally located tetracycline-responsive promoter elements (4).

Resultantly, chimeric fusion genes or bicistronic vectors that can be monitored either by bioluminescence and fluorescence (54), by small-animal PET and fluorescence (5557), by small-animal PET and bioluminescence (58), or by small-animal PET, fluorescence, and bioluminescence (59) have been used for the noninvasive imaging of reporter gene expression. PET coupled with optical imaging appears the most amenable technology. In fact, PET can provide 3-dimensional images of samples and comprehensive quantitative analyses of reporter gene expression, whereas optical bioluminescent imaging can be used to produce 2-dimensional images with high sensitivity (Table 2).

Similarly, multimodality instruments have also been developed, for example, small-animal PET/micro-CT and micro-SPECT/micro-CT (60), and instruments that permit concurrent, coregistered optical and nuclear medicine images to be obtained, using common detector systems. 


\section{APPLICATIONS OF REPORTER GENE IMAGING}

Reporter genes are genetic markers that encode easily detected proteins, and once located downstream of a specific promoter/enhancer, these markers become extraordinary tools for determining the activities of specific promoters and the factors that regulate them. The originally identified reporter genes have been widely used to study cell biology, and recent technical advancements now allow direct in vivo visualization and analyses of gene expression and regulation.

Indeed, many genes contain more than one promoter, and the activity of a promoter may be specific for a disease process. These types of promoters are of particular interest, because they represent a part of the molecular signature of a pathologic process and because they may be useful in gene therapy and imaging. By placing an imaging reporter gene under the control of such a promoter, promoter activity can be dynamically visualized (12).

\section{Gene Therapy and Targeted Gene Expression}

Gene-based therapy offers a flexible means of managing diverse types of cancer. The lack of convincing therapeutic success for currently available gene therapy protocols can be partly attributed to our inability to monitor gene expression at targeted sites in living subjects. Linking molecular imaging and gene therapy would allow real-time assessments of therapeutic processes and guide treatment protocol refinements (4). Thus an imaging reporter gene delivered and expressed in conjunction with a therapeutic gene could become a general means of monitoring in vivo gene expression $(61)$.

The expression of the therapeutic gene itself could be used for visualization with an imaging technique. HSV1 TK converts acycloguanosine prodrugs, such as acyclovir, ganciclovir, and penciclovir, into toxic compounds. Thus, HSV1 TK kills target cells when these prodrugs are administered at pharmacologic concentrations (suicidal gene therapy). The location and magnitude of HSV1-tk gene expression can be monitored repeatedly by PET, using either ${ }^{18} \mathrm{~F}-\mathrm{FHBG}$ or ${ }^{124} \mathrm{I}-$ FIAU. In addition, radiolabeled somatostatin analogs such as ${ }^{90} \mathrm{Y}$-octreotide have been used as therapeutics to treat neuroendocrine tumors overexpressing the SSTr2 gene, the location and magnitude of which can be monitored with ${ }^{111}$ In-octreotide. Moreover, NIS expression has been used both to image thyroid cancer and to concentrate ${ }^{131} \mathrm{I}$ for therapy. The possibility of NIS as an exogenous therapeutic gene has being investigated. The rationale is that $\beta$-rays will kill target cells when ${ }^{131} \mathrm{I}$ or ${ }^{188} \mathrm{Re}$ is administered at pharmacologic concentrations after NIS delivery (radionuclide gene therapy) (42). The expression of exogenous NIS gene can be evaluated using radioiodines or ${ }^{99 \mathrm{~m}} \mathrm{Tc}$-pertechnetate.

Currently, experimental findings are being transferred to clinical practice. Jacobs et al. (62) presented the first human PET image of HSV1-tk gene expression in a glioma patient. In this patient, they performed HSV1-tk suicidal gene therapy and investigated whether the gene was functionally active in human glioma tissues. Accordingly, they per- formed reporter gene imaging using ${ }^{124}$ I-FIAU before and after HSV1-tk gene transfer and confirmed the successful transfection of the HSV1-tk gene into a human tumor in vivo. More recently, an HSV1-tk- ${ }^{18}$ F-FHBG PET system was used to visualize exogenous TK activity after intratumoral injection of an HSV1-tk-containing adenovirus into patients with hepatocellular carcinomas (Fig. 3) (63).

Transcription is initiated by the activation of a gene promoter, a specific DNA sequence that can be targeted by transcription factors and RNA polymerase. Promoters that are activated specifically in certain tissue or cell types (tissue/ cell-specific promoters) are important for gene therapy (12). Honigman et al. (64) showed bioluminescence imaging of a luciferase reporter gene under control of osteoblast(BGLAP) or liver-specific $(\mathrm{C} / \mathrm{EBPb})$ promoter in transgenic animal models, and Adams et al. (65) used the tissue-specific expression of prostate-specific antigen (PSA) in prostate cancer cells. Ilagan et al. (66) used an artificial PSA enhancer/promoter to control the expression of the Fluc reporter gene, and bioluminescent images obtained successfully demonstrated the dynamics of Fluc expression in PSA-expressing tumors after the systemic administration of an adenovirus carrying the imaging reporter gene. In addition, we and other groups also developed a hepatoma-specific NIS gene expression system using $\alpha$-fetoprotein promoter $(67,68)$. Winkeler et al. (69) developed an elaborate and inducible vector system in which therapeutic and imaging reporter gene expression was simultaneously regulated by treatment with exogenous chemicals such as antibiotics or hormones. The quantitative dynamics of gene expression regulated by HSV1-sr39tk and luciferase could be monitored in vivo as well as in an in vitro cell system.

\section{Endogenous Gene Expression}

Several investigators have designed specific reporter gene constructs, under the control of upstream promoter/enhancer elements, that possess binding sites for specific transcription factors. These promoters can be activated by specific endogenous transcription factors and subsequently associate with specific endogenous genes. This strategy is referred to as the cis-promoter/enhancer reporter gene system. Once a promoter/enhancer element has been activated because of the expression or activation of an endogenous gene product, imaging reporter gene expression is induced. Thus, imaging signal intensities within target cells or tissues indicate the activities of a particular promoter/enhancer and therefore the levels of expression of a particular endogenous gene.

One example is provided by endogenous $\mathrm{p} 53$, an important endogenous antioncogenic agent. Doubrovin et al. (70) used the HSV1-tk gene, and our group (71) used the NIS gene as reporter gene to monitor transcriptional activation of $\mathrm{p} 53$. In our study, a p53RE-hNIS reporter system, in which the hNIS reporter gene was expressed under the control of an artificial enhancer p53 responsive element (p53RE), was constructed and transfected into a human hepatoma cell line. Adriamycin was used to enhance the expression of endogenous p53, and it 


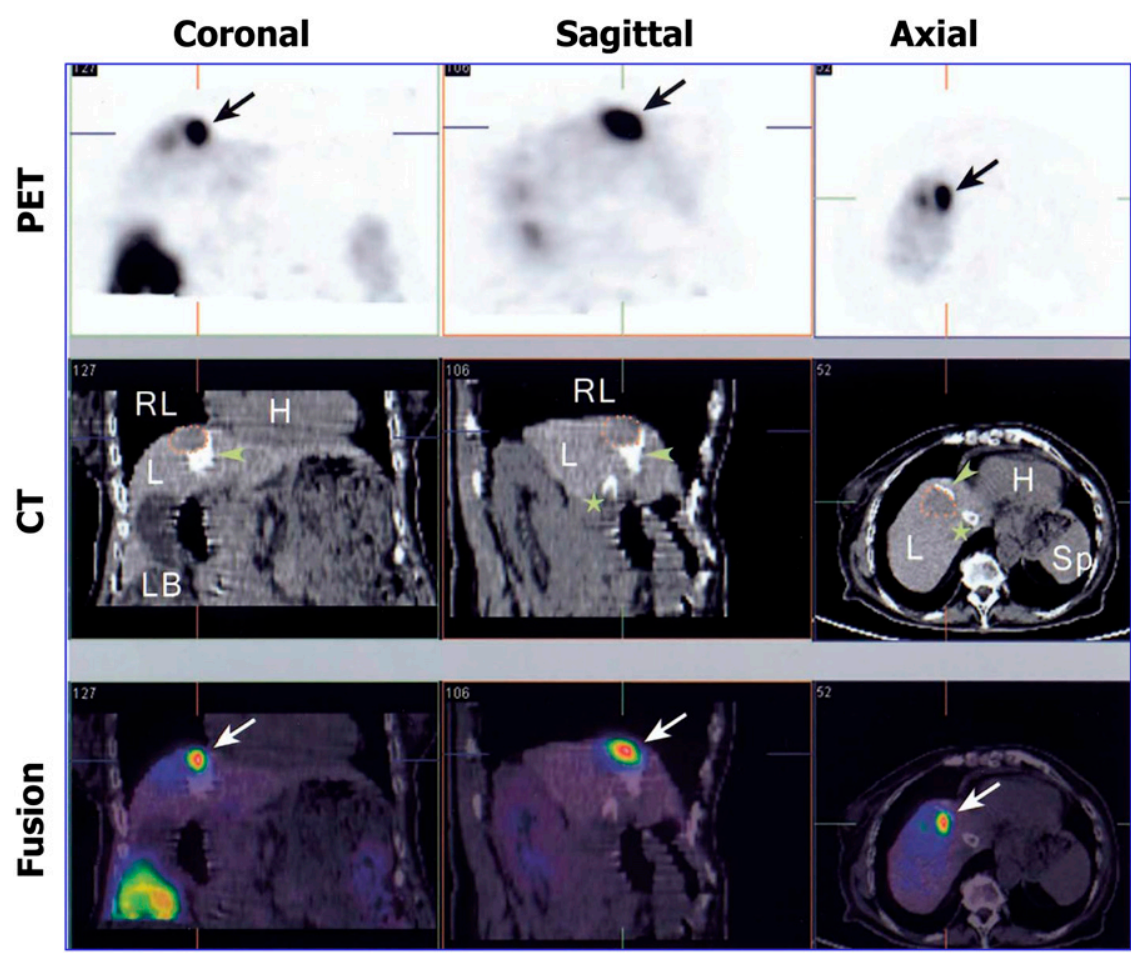

FIGURE 3. PET/CT of adenovirusmediated HSV1-tk expression in liver cancer patients. Treated tumor lesion is indicated by dotted lines on CT images, and ${ }^{18} \mathrm{~F}-\mathrm{FHBG}$ accumulation at tumor site is indicated by arrows on PET images. White spots in liver on CT images (arrowheads) correspond to lipiodol retention after transarterial embolization of tumor and installation of transjugular intrahepatic portosystemic shunt (star). $\mathrm{H}=$ heart; $\mathrm{L}=$ liver; $\mathrm{LB}=$ large bowel; $\mathrm{RL}=$ right lung; $\mathrm{Sp}=$ spleen. (Reprinted with permission of (63).) was found that adriamycin-treated cells accumulated more ${ }^{125}$ I than nontreated cells. Moreover, ${ }^{125}$ I uptake within cells increased as the adriamycin dose was increased, and this was found to correlate significantly with $\mathrm{p} 53$ levels as determined by Western blotting. Tumor xenografts of these cells also showed increased radionuclide accumulation after adriamycin treatment (Fig. 4). Several imaging studies have been conducted with specific endogenous genes, such as those for hsp and NF-kB (72-74).

\section{Intracellular Biologic Phenomenon}

Some intracellular biologic events, such as the activation of specific signal transduction pathways and nuclear receptors, can be visualized.

Transforming growth factor- $\beta$ (TGF- $\beta$ ) acts both as an inhibitor of tumor growth and as a promoter of tumor progression, and the intracellular signaling pathway of the TGF- $\beta$ receptor was imaged in Memorial Sloan-Kettering Cancer Center (75). When this receptor is bound by TGF- $\beta$, it activates a specific intracellular signal transduction pathway that results in the production of several Smad proteins. Accordingly, a HSV1-tk-GFP fusion retroviral reporter vector controlled by a promoter with a Smad binding site was constructed. This DNA construct was transfected into cancer cells, and in vivo imaging was performed using a mouse xenograft model. ${ }^{18}$ F-FEAU images visualized test tumors after injection of TGF- $\beta$, thus indicating the presence of Smad proteins and the successful signal transduction of TGF- $\beta$ and of its receptor in tumors.

We also imaged the activities of estrogen and retinoic acid nuclear receptors using a cis-promoter/enhancer reporter imaging system $(76,77)$. NIS and luciferase genes were linked with an internal ribosome entry site to simultaneously express 2 reporter genes and were placed under the control of a cis-acting retinoic acid-responsive element (RARE). In human hepatoma cells expressing this DNA construct, ${ }^{125}$ I uptake and bioluminescent intensity increased after retinoic acid treatment. Enhancement of the expression of the NIS and luciferase genes by retinoic acid has also been demonstrated in an animal tumor model by scintigraphic and optical bioluminescent imaging, respectively (Fig. 5).

To acquire the image of a reporter gene controlled by a weak promoter or enhancer, its transcriptional activity must be augmented, and an elaborate 2-step transcriptional amplification system has been designed to enhance imaging signals. In this system, a weak promoter/enhancer is used to control the expression of a potent transcriptional activator such as GAL4-VP16, which binds GAL4 binding sites and drives the expression of the reporter or therapeutic gene. Iyer et al. (78) demonstrated approximately 50- and 12-fold enhancements of firefly luciferase and HSV1-sr39tk, respectively, by the prostate-specific antigen promoter using the 2-step transcriptional amplification approach.

Three general methods are currently available for imaging protein-protein interactions in living subjects using reporter genes: the modified mammalian 2-hybrid, the bioluminescence resonance energy transfer (BRET), and the split reporter protein complementation and reconstitution strategies (79).

Luker et al. (80) made a 2-hybrid system for imaging protein-protein interactions, by using the interaction between p53-GAL4 fusion protein and large T-antigen-VP16 


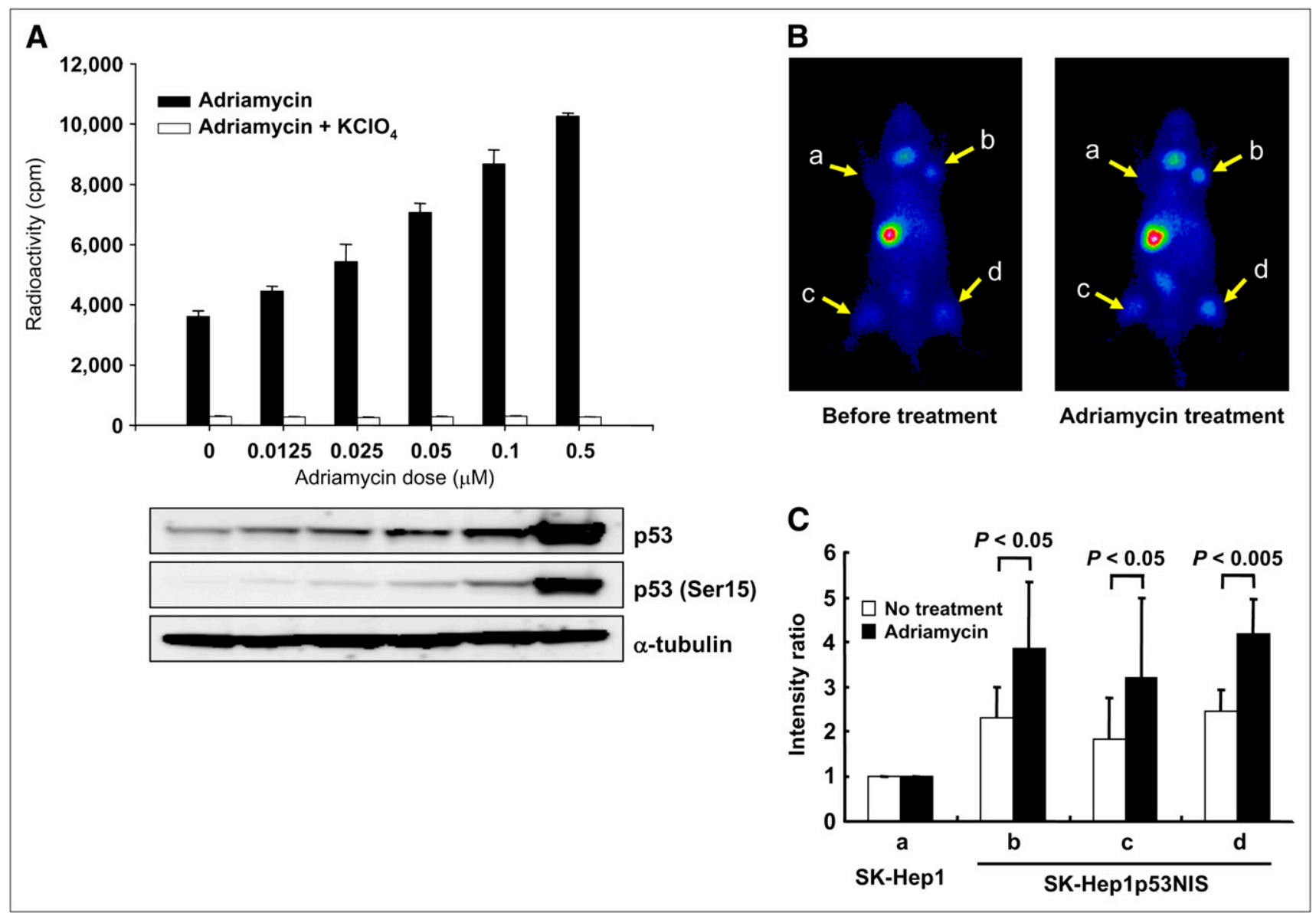

FIGURE 4. Relationship between p53 gene expression and accumulation of radioiodine in SK-Hep1 cells expressing p53RE-hNIS (SK-Hep1p53NIS) after adriamycin treatment. (A) Western blot analysis and radioiodine uptake. After treatment of SK-Hep1p53NIS cells with adriamycin, ${ }^{125} \mathrm{I}$ uptake of cells increased with increasing adriamycin dose. Levels of expression of total p53 and activated p53 (p53 Ser15) proteins increased in dose-dependent manner in SK-Hep1p53NIS cells. This increase in cells was completely inhibited by $\mathrm{KClO}_{4}$. (B) Scintigraphic images of endogenous p53 activation. Tumor xenografts were implanted in nude mice at 4 different sites: SK-Hep1 (a, $1 \times 10^{7}$, negative control); SK-Hep1p53NIS (b, $5 \times 10^{6}$; c, $1 \times 10^{7}$; d, $2 \times 10^{7}$ ). Scintigraphic images of $99 \mathrm{~m}$ Tc were obtained before and after adriamycin treatment in same mouse. Scintigraphy showed higher radioactivity in test tumors (SK-Hep1p53NIS) after adriamycin treatment than in control tumor (SK-Hep1). (C) Radioactivity ratio of SKHep1p53NIS to SK-Hep1 in mice before and after adriamycin treatment. Significantly higher uptake was observed in SKHep1p53NIS tumors than in SK-Hep1 tumor after adriamycin treatment or in nontreated SK-Hep1p53NIS tumors.

hybrid protein to activate the cellular expression of a mutant HSV1-tk reporter gene under the control of a promoter containing a GAL4 binding site. Tumors genetically modified to express these 2 fusion proteins were grown subcutaneously in the presence of doxycycline in mice. After $48 \mathrm{~h}$ of doxycycline treatment, ${ }^{18} \mathrm{~F}-\mathrm{FHBG}$ PET detected the activation of the reporter gene.

BRET technology involves the energy transfer between donor and acceptor molecules. This energy transfer primarily depends on 2 factors, that is, an overlap between the emission and excitation spectra of the donor and acceptor molecules and their proximity $(>100 \AA)$. Fluorescence resonance energy transfer (FRET)- and BRET-based technologies are assuming increasingly prominent roles in studies of protein-protein interactions (79).

Paulmurugan et al. (81) used the reactivation strategy of a split luciferase to image protein-protein interactions in a living mouse. They split a whole luciferase enzyme into $\mathrm{C}$ - and $\mathrm{N}$-terminal fragments, and its $\mathrm{C}$-terminal and $\mathrm{N}$-terminal domains were bound to protein pair $\mathrm{MyoD}$ and ID, respectively. As a result of a protein interaction between MyoD and ID, the 2 luciferase fragments fused to become a functional luciferase, which could be visualized by CCD cameras.

In addition, Zhang et al. (82) designed a hybrid bioluminescence Akt reporter system containing an Akt-phosphorylated peptide sequence flanked by $\mathrm{N}$-terminal and $\mathrm{C}$-terminal domains of the firefly luciferase reporter to measure Akt activity. In the presence of Akt kinase activity, phosphorylation of an Akt peptide sequence would result in its interaction with an adjacent Akt-phosphorylated residues binding domain, thus sterically preventing reconstitution of split $\mathrm{N}$-terminal and $\mathrm{C}$-terminal luciferase domains. In the absence of Akt activity, loss of steric hindrance would 
A
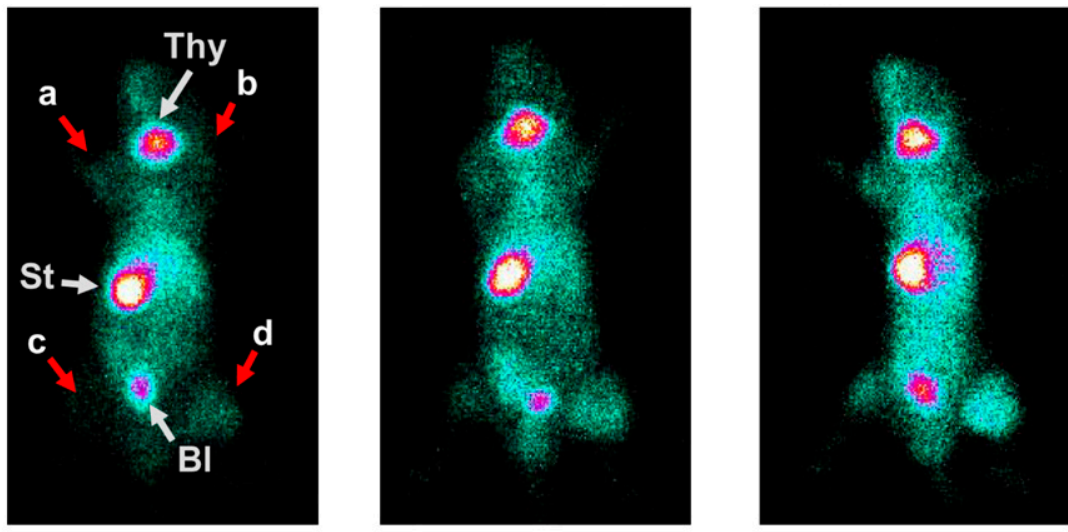

B

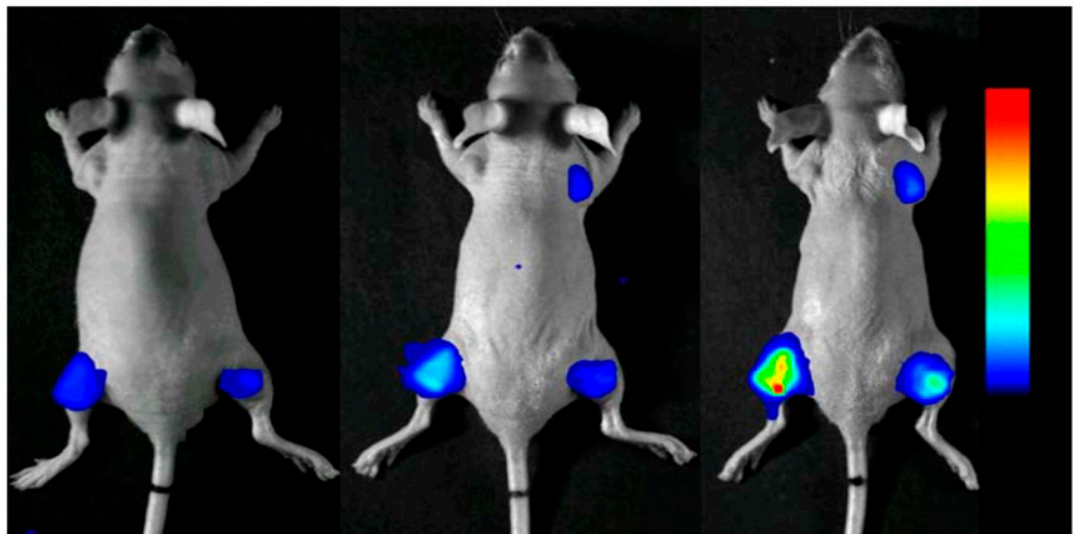

No treatment
$24 \mathrm{~h}$

$48 \mathrm{~h}$

After ATRA treatment

FIGURE 5. $\quad{ }^{99 m}$ Tc scintigraphic images (A) and bioluminescent images (B) of nude mice bearing SK-Hep1 and SKHep1/RARE/NIS-Luc tumors before and after all-trans-retinoic acid (ATRA) treatment. Tumor xenografts derived from SK-Hep1 cells (a, $1 \times 10^{7}$, wild type) and SK-Hep1/RARE/NIS-Luc cells (b, $1 \times 10^{6} ; \mathrm{c}, 1 \times 10^{7} ; \mathrm{d}, 1 \times 10^{8}$ ) were grown in nude mice. (A) Serial planar $\gamma$-camera images of same mouse show increased radioactivity after ATRA treatment in SK-Hep1/RARE/NIS-Luc tumors but not in SK-Hep1 tumor. (B) Serial optical images of same mouse show increased optical signal after ATRA treatment in SK-Hep1/RARE/NIS-Luc tumors but not in SK-Hep1 tumor. BI = bladder; St $=$ stomach; Thy $=$ thyroid. allow the reconstitution of split luciferase domains, and then luciferase activity could be detected in vivo as well as in vitro.

To date, several reporter proteins (e.g., $\beta$-lactamase, $\beta$-galactosidase, ubiquitin, dihydrofolate reductase, Fluc, Rluc, and GFP) have been adapted for use in split protein strategies by identifying various split sites in each reporter protein (79).

\section{Monitoring Tumor Mass}

Noninvasive reporter imaging gene expression offers excellent opportunities to understand cancer progression, metastasis, and therapy in whole animals. Using cancer cells stably transfected with imaging reporter genes, individual animals can be visually monitored for tumor burden at primary sites, and thus, differences in tumor progression rates can be determined. Moreover, the presence of metastases can be queried, and individual responses to alternative therapies can be repeatedly monitored. A large number of engrafted tumor models has been marked with optical or nuclear medicine reporter genes and subsequently followed to determine tumor burden and response to therapy. Tumor transplants expressing GFP, HSV1 TK, and firefly luciferase have all been used for this purpose (11). Because of the convenience of monitoring tumor sites within the same mouse, luciferase bioluminescence is the most widely used method for repeatedly monitoring xenograft responses to therapies (83).

We transfected the hNIS gene and Fluc gene under constitutive cytomegalovirus promoter into human hepatoma cells. Using animal models, the effects of anticancer therapeutic regimens can be monitored by scintigraphy and optical imaging. An excellent correlation $\left(R^{2}=0.99\right)$ was found between accumulated radioiodine activity in cells and viable cancer cell numbers. Reporter imaging using the NIS gene reflected viable cancer cell numbers and allowed changes in cell numbers induced by anticancer treatment to be detected. ${ }^{99 m}$ Tc scintigraphy and bioluminescent imaging showed moderate correlations between tumor weight and imaging signals such as radioactivity and bioluminescent intensity in living animals (Fig. 6) (84). We consider that radioactivity and optical intensity from the tumors reflect viable cancer cell numbers more accurately than tumor weight, because tumor tissues also contain immune cells and necrotic and fibrous tissues as well as viable cancer cells. Furthermore, our group developed a lentiviral vector system carrying hNIS gene under UbC promoter that allows stable and long-term gene expression in vitro and in vivo, which can be useful in long-term monitoring of tumor burden (85). 


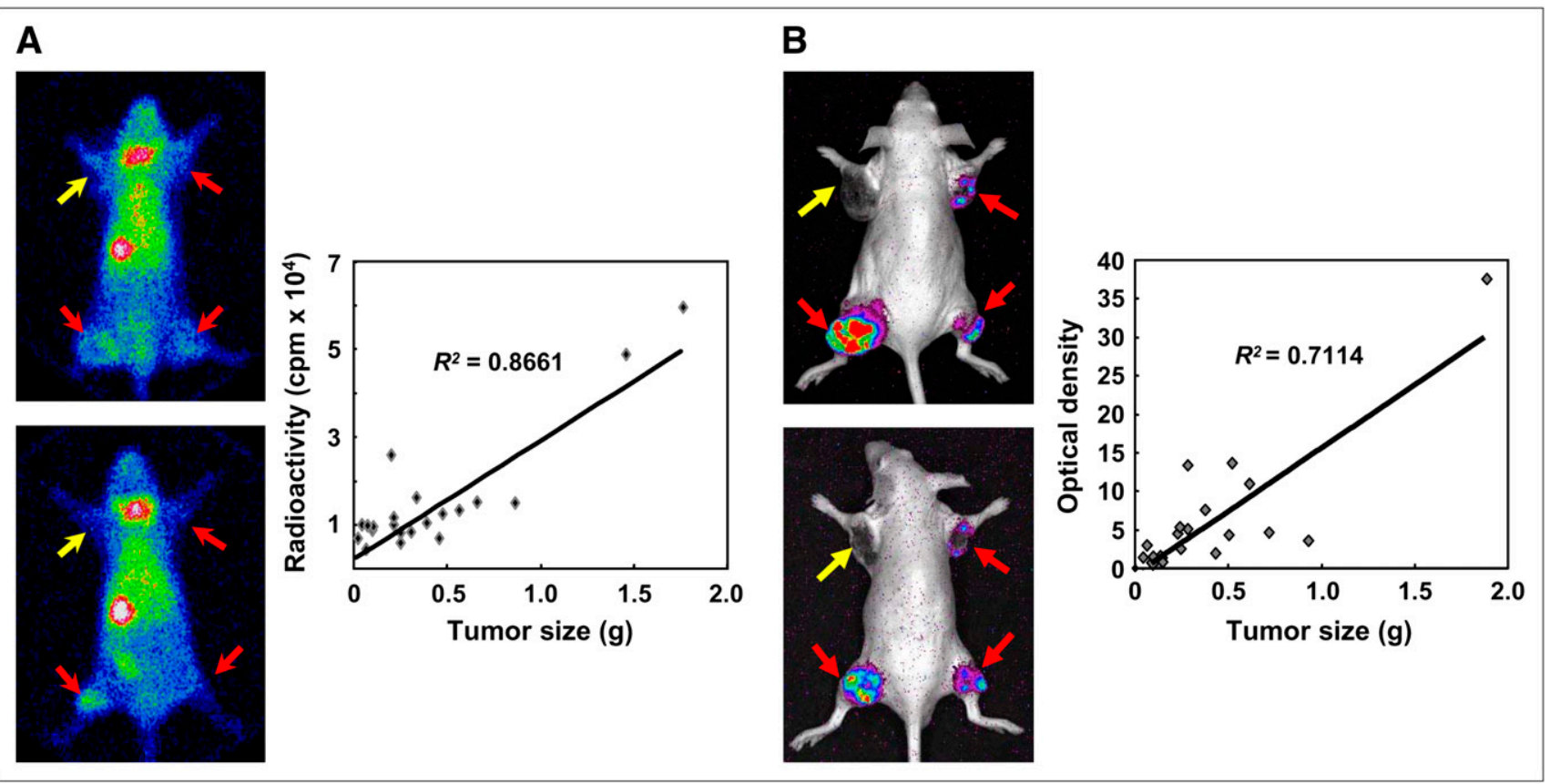

FIGURE 6. Correlation between imaging signals from tumors and tumor weight. SK-Hep1 and SK-Hep1/NIS-Luc cells expressing simultaneously NIS and luciferase genes were implanted as xenografts into left shoulder (SK-Hep1; $5 \times 10^{6}$ cells), right shoulder (SK-Hep1/NIS-Luc; $5 \times 10^{6}$ cells), left thigh (SK-Hep1/NIS-Luc; $1 \times 10^{7}$ cells), and right thigh (SK-Hep1/NIS-Luc; $5 \times 10^{6}$ cells). (A) $99 \mathrm{mTc}$ scintigraphic images show increased radioactivity in SK-Hep1/NIS-Luc tumors but not in SK-Hep1 tumor. After acquisition of scintigraphic images, mice were sacrificed, and biodistribution of radioactivity was examined. Correlation between tumor weight and radioactivity of each tumor is shown $\left(R^{2}=0.8661\right)$. (B) Bioluminescent images show viable tumor burden of SKHep1/NIS-Luc tumors but not of SK-Hep1 tumor. Correlation between bioluminescence signal and tumor weight was moderate $\left(R^{2}=0.7114\right)$.

\section{Cell Therapy}

Molecular imaging using reporter gene can also be applied to the monitoring of the in vivo distributions of target or therapy cells, such as immune cells and stem cells. The imaging of targeted T-cell trafficking using luciferase bioluminescence has been demonstrated in several autoimmunity models, including collagen-induced arthritis (86) and experimental autoimmune encephalomyelitis (87).

The noninvasive imaging of adoptively administered cells provides opportunities to study cell trafficking, homing, tumor targeting, activation, proliferation, and persistence, and the ability to repeatedly monitor the location, expansion, and viability of engrafted, tumor-targeted lymphocytes would be of great value $(55,88,89)$. This technique can be used in protocols designed to optimize preferential T-cell tumor targeting, to reduce nonspecific cell distribution, to enhance lymphocyte residence times at tumor sites, and to facilitate the expansion of a targeted lymphocyte population after transplantation (11).

Moreover, it would be of considerable value if the antigendependent activation states during immune responses could be monitored noninvasively. Ponomarev et al. (90) transfected the HSV1-tk-GFP fusion vector under the control of a nuclear factor of activated $\mathrm{T}$ cells (NFAT)-responsive promoter into a human T-cell line. Cells were selected by flow cytometry, for NFAT induction of GFP expression in response to T-cell activation, and anti-CD28 and anti-CD3 were administered after establishing subcutaneous tumors in nude rats. Therefore, NFAT-mediated T-cell activation was visualized by PET using ${ }^{124}$ I-FIAU.

The transplantation of cells such as stem cells and progenitor cells into damaged tissues has tremendous therapeutic potential in several disorders. After the systemic or local injection of stem cells, they may be able to migrate and repopulate in pathologic sites. Reporter gene imaging techniques have been used to monitor cells and can provide information on 3 important features of cellular implants, that is, cell tracking, viability, and numbers (91). After the stable transfection of stem cells with imaging reporter genes, a suitable imaging probe could visualize their distribution and permit longitudinal monitoring of cell survival.

The location, magnitude, and survival duration of embryonic cardiomyoblasts were monitored noninvasively using the HSV1-tk and luciferase genes (Fig. 7) (92). In addition, we transfected the NIS and Fluc genes into F-3 human neural stem cells and found increased imaging signals from the cells; this result suggested the possibility of visualizing stem cell migration (93).

The successful differentiation of stem cells from mature functional cells is another critical feature of stem cell therapies, but this too can be visualized using reporter genes. Our group prepared a NIS-Luc expression construct in which NIS and Luc gene expression is simultaneously controlled by a neuron-specific enolase (NSE) promoter and transfected this 


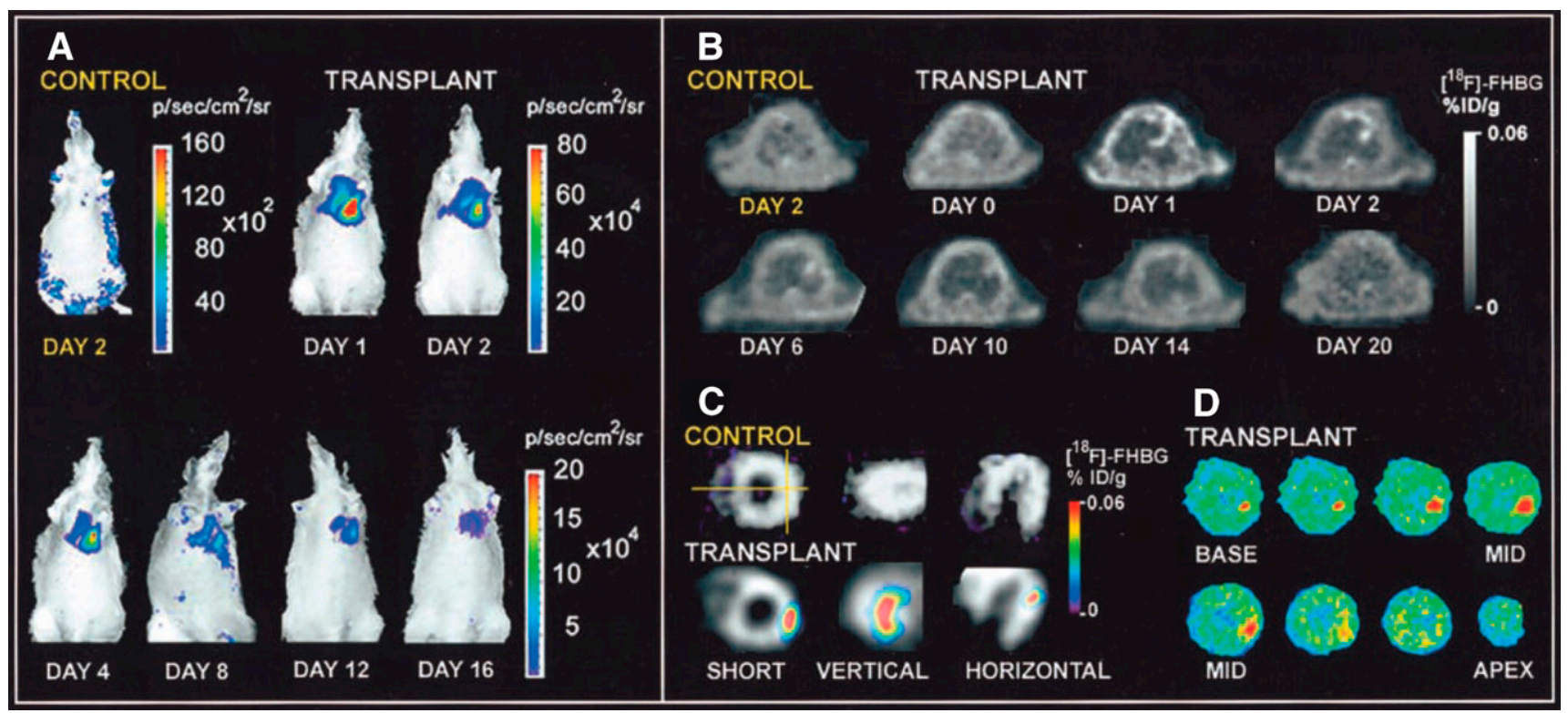

FIGURE 7. Molecular imaging of cardiac cell transplantation in rat using optical bioluminescence and PET. (A) After transplantation into rat of embryonic cardiomyoblasts expressing luciferase gene, luciferase images were obtained for $16 \mathrm{~d}$ at cardiac site. Control rat showed background signal only. (B) After transplantation with cardiomyoblasts expressing HSV1-sr39tk reporter gene, location(s), magnitude, and duration of gene expression could be monitored by PET with ${ }^{18} \mathrm{~F}-\mathrm{FHBG}$ (gray scale). (C) Representative rat with transplant had significant activity at lateral wall, as shown by ${ }^{18} \mathrm{~F}-\mathrm{FHBG}$ image (color scale) overlaid on ${ }^{13} \mathrm{~N}-$ $\mathrm{NH}_{3}$ perfusion image (gray scale). Control rat had homogeneous ${ }^{13} \mathrm{~N}-\mathrm{NH}_{3}$ perfusion but background ${ }^{18} \mathrm{~F}-\mathrm{FHBG}$ activity. (D) Autoradiography of same rat confirmed accumulation of ${ }^{18} \mathrm{~F}-\mathrm{FHBG}$ at lateral wall. $\% \mathrm{ID} / \mathrm{g}=$ percentage injected dose per gram. (Reprinted with permission of (92).)

into neural stem cells. After these cells had been treated in vitro with cyclic adenosine triphosphate, which induces neural differentiation, we observed increased optical signals and accumulation of radioiodine. We also performed an in vivo animal experiment to visualize neuronal differentiation using a reporter driven by an NSE promoter (94).

\section{Drug Development}

Reporter gene imaging techniques provide a new means of identifying drug targets and of preclinical testing (50). The ability to noninvasively image endogenous gene expression and various intracellular biologic phenomena, such as signal transduction (75), nuclear receptor activation $(76,77)$, and protein-protein interactions (79), has important implications for drug discovery.

It has become evident that molecular imaging will fulfill a central role in the process of drug development. The generation of reporters for targeted drug delivery, and interchangeability between in vitro and in vivo screens and assays, have become integral components of rational and screen-based drug design strategies and will undoubtedly accelerate the drug development process and ease the transition from purified targets to cells, animals, and humans (53).

Current reporter gene strategies, based on a suitable promoter, can provide new information on the level, timing, and duration of action of many biologically active transgene products. The selection of optimal promoters for reporter gene expression control should be carefully considered when monitoring the anticancer effects of drugs on cells. As an example, Kim et al. (95) recently reported that genotoxic stress, such as that induced by adriamycin, enhanced transgene expression via NF- $\mathrm{kB}$ activation, and strong viral promoter (cytomegalovirus promoter) has consensus binding sites for NF- $\kappa \mathrm{B}$ in its enhancer region.

Reporter gene imaging has emerged as a useful means of monitoring tumor growth and regression in preclinical models $(96,97)$. Tumors stably expressing Fluc implanted at subcutaneous, orthotopic, or intraperitoneal sites can be effectively imaged using an optical CCD camera. Recently, our group described tumor growth inhibition induced by hMUC1 vaccination and by a combination of hMUC1 vaccination and hNIS radioiodine gene therapy in immunocompetent mice by bioluminescent imaging $(98,99)$. Similarly, the cytoreductive effects of chemotherapeutics have been successfully monitored by measuring image intensity reductions $(100,101)$.

\section{Transgenic Animals}

A transgenic mouse with a specific reporter gene can be produced by injecting the gene fragment of interest into fertilized eggs and by subsequently selecting positive founders by southern blotting or genomic PCR to confirm the presence of the injected gene in the host animal genome. Maggi et al. (102) stated that a suitable transgenic animal should enable the rapid assessment of all organs in which a given gene is active, the measurement of the drug response in various tissues, the evaluation of the minimal concentration of drug necessary to obtain the desired pharmacologic response independently of its plasma levels, and the discovery of active metabolites and their action profiles. 
The estrogen-responsive element-Luc transgenic mouse, in which all cells possess the Luc gene and estrogen receptor enhancer, is one example of a reporter animal that can be used for drug development. This mouse model was specifically made to study and develop ligands that activate via nuclear estrogen receptor binding, can report on the generalized state of estrogen receptor activity, and be used in studies on the dynamics of estrogen receptor activity. It has been demonstrated that this model system is sensitive enough to detect responses to low, physiologic concentrations of various ligands (102).

Transgenic mice have been used for toxicologic analyses; for example, to test genotoxicity (103) or to signal the presence of toxic inorganic compounds through reporter gene expression driven by hsp70 promoter $(104,105)$. Other models are planned for the evaluation of the enzymatic system responsible for drug metabolism in the liver $(102,106)$. To evaluate prostate cancer progression in animal models, Iyer et al. (107) generated a transgenic mouse model of luciferase gene expression controlled by the PSA promoter in living mice using bioluminescence imaging. The bioluminescence signal in the prostate was detected as early as $3 \mathrm{wk}$ of age and showed prostate-specific expression. They also demonstrated that blocking androgen activity could downregulate luciferase expression in the prostate. In the near future, efforts will be aimed at devising animal testing strategies that provide comprehensive pharmacodynamic, pharmacokinetic, and possibly toxicologic information in a single step, which would lead to more efficient and rational screening and considerable drug development cost and time reductions.

Transgenic mice can also be used to investigate stem cell therapies. Cao et al. (108) produced transgenic mice expressing firefly luciferase controlled by $\beta$-actin promoter and monitored engrafted hematopoietic stem cells in irradiated recipient mice in real time by bioluminescent imaging. After stem cells have migrated to target tissue, their differentiation to mature functional cells is critical for successful therapy. We have developed a transgenic mouse model to image cardiomyocyte differentiation using $\alpha$-myosin heavy-chain (MHC) promoter as a differentiation marker and NIS as a reporter gene (109); $\alpha$-MHC promoter is a differentiated cardiomyocyte specific regulator of gene expression. Dynamic scintigraphy using ${ }^{131} \mathrm{I}$ in transgenic mice showed rapid and intense radioiodine uptake only in the myocardium, thus demonstrating the functional activation of $\alpha-\mathrm{MHC}$ (Fig. 8). This transgenic mouse model should be useful for myocardial stem cell differentiation studies. By injecting bone marrow-derived stem cells from these transgenic animals into other animals with a myocardial infarct, radioiodines or ${ }^{99 m}$ Tc scintigraphy can be used to confirm the stem cell differentiation to mature functional cardiomyocytes.

\section{Others}

To monitor infections with bacteria or viruses, molecular imaging techniques using reporter gene expression will be

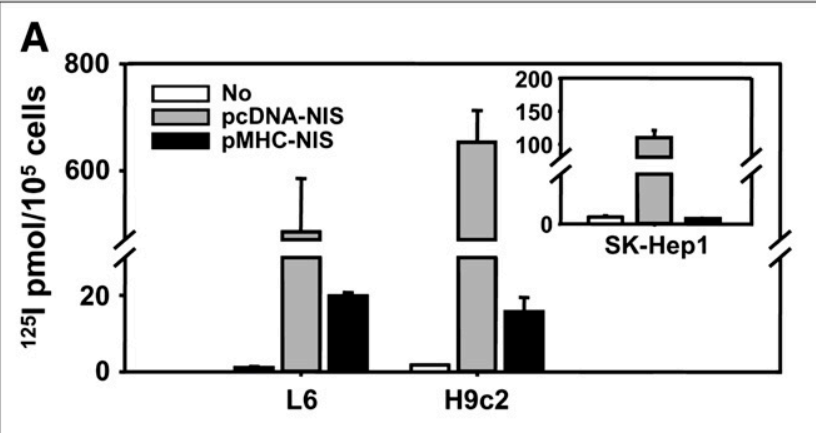

B

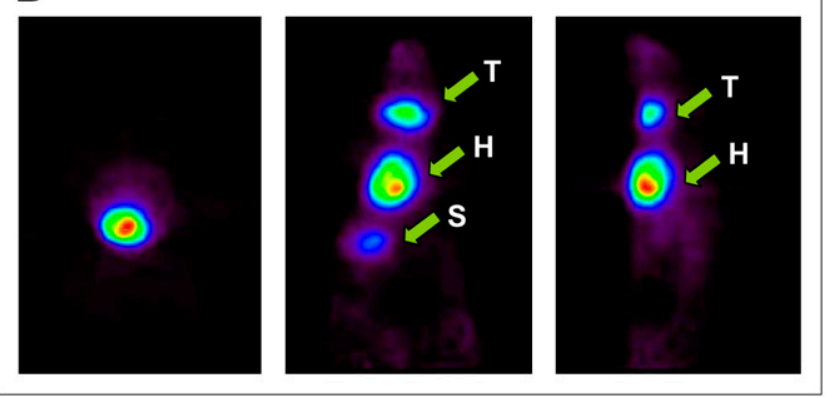

FIGURE 8. Development of NIS-transgenic mice for cardiomyocyte-specific reporter gene expression. (A) To verify celltype-specific expression of pMHC-NIS vector, pMHC-NIS was transfected into 2 rat myoblast cell lines, L6 and H9c2, and human hepatoma cell line, SK-Hep1. Transfected L6 and H9c2 cells showed 20 -fold- and 10 -fold-higher ${ }^{125}$ I uptake than their parental cells, but hepatoma did not (inset). Therefore, the MHC promoter was confirmed to be active only in cardiomyocytes. (B) Small-animal PET image obtained for transgenic mouse with ${ }^{124}$ (left, transverse; center, coronal; right, sagittal). Transgenic mouse showed higher uptake of ${ }^{124} \mathrm{I}$ in heart $(\mathrm{H})$ than in thyroid (T) or stomach (S). pcDNA-NIS = control.

helpful. Encephalitis caused by HSV infection in rat brain could be monitored quantitatively using ${ }^{14} \mathrm{C}-\mathrm{FMAU}$ and autoradiographic mapping (110). To evaluate the efficiency of molecular therapies with oncolytic HSV treatment in cancer, PET with ${ }^{124}$ I-FIAU was applied for determination of distribution and magnitude of viral infections $(111,112)$. The noninvasive, rapid, and continuous method for monitoring bacterial infection in real time was developed (113). Bacterial infection could be monitored by bioluminescent images with Staphylococcus aureus isolate expressing a modified lux operon in the bacterial chromosome. This bioluminescent reporter bacterium was used to investigate the progression of bacterial infection in living animals and to study the antimicrobial effects of various antibiotics. In addition, Min et al. (114) reported that lux-expressing Escherichia coli can target various tumors, including metastases, enabling noninvasive visualization of both tumors and metastases.

\section{CONCLUSION}

There is an ever-increasing knowledge of the critical biologic pathways involved in oncogenesis and cancer progression, which has stimulated the development of 
molecular-genetic imaging. On the other hand, molecular imaging has already become an indispensable tool in basic oncology research, and its application should increase our knowledge of the various molecular phenomena in cancer cells (4). Reporter gene imaging techniques can be used as a noninvasive convenient method to evaluate gene expression, signal transduction, protein-protein interaction, receptor activation, and several molecular events. In addition, it makes many animal research experiments simple by repetitive temporal observation of molecular-genetic phenomena in the same animals.

The remarkable efforts currently being made to progress molecular imaging technologies demonstrate its perceived importance and range of applications. Continued improvements in instrumentation, identification of novel targets and genes, and the availability of improved imaging probes ensure that molecular-genetic imaging will play an increasingly important role in the diagnosis and therapy of cancer. Moreover, dual- or triple-reporter constructs embracing optical, MRI, and nuclear medicine provide multimodality imaging and should ease the transition from the laboratory to the clinical level.

Until now, reporter gene imaging has been used in the clinic only to visualize exogenous gene expression $(62,63)$. Impending clinical application is expecting in the fields of cell therapy, including stem cell and adoptive cell therapies, and there are several potentially applicable imaging genes and probes to be approved by the government authority. For this reason, the clinical applications of reporter gene imaging will expand as new reporter systems, both genes and imaging probes, become "humanized" and safer. In parallel, concomitant developments are required to produce more efficient, safer vector systems capable of delivering and targeting transgenes to selected organs and tissues.

Molecular imaging is expected to play an increasing role in the personalized health care and therapy of tomorrow and will accelerate the transition from bench to bedside. To achieve this vision, multidisciplinary team approaches are vital. Efficient communication and cooperation within such networks are equally essential, and nuclear medicine physicians and scientists should be in the center (12).

\section{ACKNOWLEDGMENTS}

This work was supported in part by a grant (SC3070) from the Stem Cell Research Center of the 21st Century Frontier Research Program funded by the MOST. We thank Dr. Keon Wook Kang, Dr. Jae Sung Lee, and Dr. Soon Hag Kim for helping with the preparation of this article.

\section{REFERENCES}

1. Blasberg RG, Gelovani-Tjuvajev J. In vivo molecular-genetic imaging. J Cell Biochem Suppl. 2002;39:172-183.

2. Tjuvajev JG, Stockhammer G, Desai R, et al. Imaging the expression of transfected genes in vivo. Cancer Res. 1995;55:6123-6132.

3. Gambhir SS, Barrio JR, Phelps ME, et al. Imaging adenoviral-directed reporter gene expression in living animals with positron emission tomography. Proc Natl Acad Sci USA. 1999;96:2333-2338.
4. Iyer M, Sato M, Johnson M, Gambhir SS, Wu L. Applications of molecular imaging in cancer therapy. Curr Gene Ther. 2005;5:607-618.

5. Dewanjee MK, Ghafouripour AK, Kapadvanjwala M, et al. Noninvasive imaging of c-myc oncogene messenger RNA with indium-111-antisense probes in a mammary tumor-bearing mouse model. J Nucl Med. 1994;35:1054-1063.

6. Tavitian B, Terrazzino S, Kuhnast B, et al. In vivo imaging of oligonucleotides with positron emission tomography. Nat Med. 1998;4:467-471.

7. Lewis MR, Jia F. Antisense imaging: and miles to go before we sleep? J Cell Biochem. 2003;15:464-472.

8. Serganova I, Blasberg RG. Multi-modality molecular imaging of tumors. Hematol Oncol Clin North Am. 2006;20:1215-1248.

9. Contag $\mathrm{CH}$, Spilman SD, Contag PR, et al. Visualizing gene expression in living mammals using a bioluminescent reporter. Photochem Photobiol. 1997; 66:523-531.

10. Contag CH, Jenkins D, Contag PR, Negrin RS. Use of reporter genes for optical measurements of neoplastic disease in vivo. Neoplasia. 2000;2:41-52.

11. Herschman HR. Noninvasive imaging of reporter gene expression in living subjects. Adv Cancer Res. 2004;92:29-80.

12. Rome C, Couillaud F, Moonen CT. Gene expression and gene therapy imaging. Eur Radiol. 2007; 17:305-319.

13. Garofalakis A, Zacharakis G, Meyer H, et al. Three-dimensional in vivo imaging of green fluorescent protein-expressing $\mathrm{T}$ cells in mice with noncontact fluorescence molecular tomography. Mol Imaging. 2007;6:96-107.

14. Wood KV, Lam YA, Seliger HH, McElroy WD. Complementary DNA coding click beetle luciferases can elicit bioluminescence of different colors. Science. 1989;244:700-702.

15. Lorenz WW, McCann RO, Longiaru M, et al. Isolation and expression of a cDNA encoding Renilla reniformis luciferase. Proc Natl Acad Sci USA. 1991; 88:4438-4442.

16. Bryan BJ, Szent-Gyorgyi CS. May 2001. U.S. patent 6232107.

17. Muller-Taubenberger A. Application of fluorescent protein tags as reporters in live-cell imaging studies. Methods Mol Biol. 2006;346:229-246.

18. Chudakov DM, Lukyanov S, Lukyanov KA. Fluorescent proteins as a toolkit for in vivo imaging. Trends Biotechnol. 2005;23:605-613.

19. Troy T, Jekic-McMullen D, Sambucetti L, et al. Quantitative comparison of the sensitivity of detection of fluorescent and bioluminescent reporters in animal models. Mol Imaging. 2004;3:9-23.

20. Weissleder R. Scaling down imaging: molecular mapping of cancer in mice. Nat Rev Cancer. 2002;2:11-18.

21. Gilad AA, Winnard PT Jr, Van Zijl PC, Bulte JW. Developing MR reporter genes: promises and pitfalls. NMR Biomed. 2007;20:275-290.

22. Koretsky A, Lin Y-J, Schorle H, Jaenisch R. Genetic control of MRI contrast by expression of the transferrin receptor. In: Proceedings of the International Society of Magnetic Resonance Medicine. Berkeley, CA: ISMRM; 1996;4:69.

23. Louie AY, Huber MM, Ahrens ET, et al. In vivo visualization of gene expression using magnetic resonance imaging. Nat Biotechnol. 2000;18:321-325.

24. Weissleder R, Simonova M, Bogdanova A, et al. MR imaging and scintigraphy of gene expression through melanin induction. Radiology. 1997;204:425-429.

25. Alfke H, Stoppler H, Nocken F, et al. In vitro MR imaging of regulated gene expression. Radiology. 2003;228:488-492.

26. Cohen B, Dafni H, Meir G, et al. Ferritin as an endogenous MRI reporter for noninvasive imaging of gene expression in C6 glioma tumors. Neoplasia. 2005; 7:109-117.

27. Genove G, DeMarco U, Xu H, Goins WF, Ahrens ET. A new transgene reporter for in vivo magnetic resonance imaging. Nat Med. 2005;11:450-454.

28. Gilad AA, McMahon MT, Walczak P, et al. Artificial reporter gene providing MRI contrast based on proton exchange. Nat Biotechnol. 2007;25:217-219.

29. Kim JS, Lee JS, Im KC, et al. Performance measurement of the microPET Focus 120. J Nucl Med. 2007;48:1527-1535.

30. Townsend DW, Carney JP, Yap JT, Hall NC. PET/CT today and tomorrow. J Nucl Med. 2004;45(suppl):4S-14S.

31. Pichler BJ, Judenhofer MS, Catana C, et al. Performance test of an LSO-APD detector in a 7-T MRI scanner for simultaneous PET/MRI. J Nucl Med. 2006;47:639-647.

32. Gambhir SS, Bauer E, Black ME, et al. A mutant herpes simplex virus type 1 thymidine kinase reporter gene shows improved sensitivity for imaging reporter gene expression with positron emission tomography. Proc Natl Acad Sci USA. 2000;97:2785-2790.

33. Ponomarev V, Doubrovin M, Shavrin A, et al. A human-derived reporter gene for noninvasive imaging in humans: mitochondrial thymidine kinase type 2 . J Nucl Med. 2007;48:819-826.

34. MacLaren DC, Gambhir SS, Satyamurthy N, et al. Repetitive, noninvasive imaging of the dopamine $\mathrm{D} 2$ receptor as a reporter gene in living animals. Gene Ther: 1999;5:785-791. 
35. Kummer C, Winkeler A, Dittmar C, et al. Multitracer positron emission tomographic imaging of exogenous gene expression mediated by a universal herpes simplex virus 1 amplicon vector. Mol Imaging. 2007;6:181-192.

36. Furukawa T, Lohith TG, Takamatsu S, Mori T, Tanaka T, Fujibayashi Y. Potential of the FES-hERL PET reporter gene system: basic evaluation for gene therapy monitoring. Nucl Med Biol. 2006;33:145-151.

37. Rogers BE, Zinn KR, Buchsbaum DJ. Gene transfer strategies for improving radiolabeled peptide imaging and therapy. $Q$ J Nucl Med. 2000;44: 208-223.

38. Haberkorn U, Altmann A, Mier W, Eisenhut M. Impact of functional genomics and proteomics on radionuclide imaging. Semin Nucl Med. 2004;34:4-22.

39. Rogers BE, McLean SF, Kirkman RL, et al. In vivo localization of $\left[{ }^{111} \mathrm{In}\right]-$ DTPA-D-Phe1-octreotide to human ovarian tumor xenografts induced to express the somatostatin receptor subtype 2 using an adenoviral vector. Clin Cancer Res. 1999;5:383-393.

40. Altmann A, Kissel M, Zitzmann S, et al. Increased MIBG uptake after transfer of the human norepinephrine transporter gene in rat hepatoma. J Nucl Med. 2003;44:973-980.

41. Haberkorn U. Gene therapy with sodium/iodide symporter in hepatocarcinoma. Exp Clin Endocrinol Diabetes. 2001;1:60-62.

42. Chung JK. Sodium/iodide symporter: its role in nuclear medicine. J Nucl Med. 2002;43:1188-1200.

43. Shin JH, Chung J-K, Kang JH, et al. Feasibility of sodium/iodide symporter (NIS) gene as a new imaging reporter gene: comparison with HSV1-tk. Eur J Nucl Med. 2003;31:425-432.

44. Moroz MA, Serganova I, Zanzonico P, et al. Imaging hNET reporter gene expression with ${ }^{124}$ I-MIBG. J Nucl Med. 2007;48:827-836.

45. Dai G, Levy O, Carrasco N. Cloning and characterization of the thyroid iodide transporter. Nature. 1996;379:458-460.

46. Smanik PA, Lui Q, Furminger TL, et al. Cloning of the human sodium iodide symporter. Biochem Biophys Res Commun. 1996;226:339-345.

47. Levy O, De la Vieja A, Ginter CS, Riedel C, Dai G, Carrasco N. N-linked glycosylation of the thyroid $\mathrm{Na}^{+} / \mathrm{I}^{-}$symporter (NIS): implications for its secondary structure model. J Biol Chem. 1998;273:22657-22663.

48. Van Sande J, Massart C, Beauwens R, et al. Anion selectivity by the sodium iodide symporter. Endocrinology. 2003;144:247-252.

49. Contag $\mathrm{CH}$, Bachmann $\mathrm{MH}$. Advances in in vivo bioluminescence imaging of gene expression. Annu Rev Biomed Eng. 2002;4:235-260.

50. Ottobrini L, Ciana P, Biserni A, Lucignani G, Maggi A. Molecular imaging: a new way to study molecular processes in vivo. Mol Cell Endocrinol. 2006;246: 69-75.

51. Jeon YH, Choi Y, Kang JH, et al. Immune response to firefly luciferase as a naked DNA. Cancer Biol Ther. 2007;6:781-786.

52. Stripecke R, Carmen Villacres M, Skelton D, Satake N, Halene S, Kohn D. Immune response to green fluorescent protein: implications for gene therapy. Gene Ther. 1999;6:1305-1312.

53. Gross S, Piwnica-Worms D. Molecular imaging strategies for drug discovery and development. Curr Opin Chem Biol. 2006;10:334-342.

54. Wang Y, Yu YA, Shabahang S, Wang G, Szalay AA. Renilla luciferaseAequorea GFP (Rluc-GFP) fusion protein, a novel dual reporter for real-time imaging of gene expression in cell cultures and in live animals. Mol Genet Genomics. 2002;268:160-168.

55. Dubey P, Su H, Adonai N, et al. Quantitative imaging of the T cell antitumor response by positron-emission tomography. Proc Natl Acad Sci USA. 2003; 100:1232-1237.

56. Ponomarev V, Doubrovin M, Serganova I, et al. Cytoplasmically retargeted HSV1-tk/GFP reporter gene mutants for optimization of noninvasive molecular-genetic imaging. Neoplasia. 2003;5:245-254.

57. Jacobs A, Dubrovin M, Hewett J, et al. Functional coexpression of HSV-1 thymidine kinase and green fluorescent protein: implications for noninvasive imaging of transgene expression. Neoplasia. 1999;1:154-161.

58. De A, Lewis XA, Gambhir SS. Noninvasive imaging of lentiviral-mediated reporter gene expression in living mice. Mol Ther. 2003;7:681-691.

59. Ray P, Tsien R, Gambhir SS. Construction and validation of improved triple fusion reporter gene vectors for molecular imaging of living subjects. Cancer Res. 2007;67:3085-3093.

60. Goertzen AL, Meadors AK, Silverman RW, Cherry SR. Simultaneous molecular and anatomical imaging of the mouse in vivo. Phys Med Biol. 2002; 47:4315-4328.

61. Wu L, Johnson M, Sato M. Transcriptionally targeted gene therapy to detect and treat cancer. Trends Mol Med. 2003;9:421-429.

62. Jacobs A, Voges J, Reszka R, et al. Positron-emission tomography of vectormediated gene expression in gene therapy for gliomas. Lancet. 2001;9283:727729.
63. Penuelas I, Mazzolini G, Boan JF, et al. Positron emission tomography imaging of adenoviral-mediated transgene expression in liver cancer patients. Gastroenterology. 2005;128:1787-1795.

64. Honigman A, Zeira E, Ohana $\mathrm{P}$, et al. Imaging transgene expression in live animals. Mol Ther. 2001;4:239-249.

65. Adams JY, Johnson M, Sata M, et al. Visualization of advanced human prostate cancer lesions in living mice by a targeted gene transfer vector and optical imaging. Nat Med. 2002;8:891-897.

66. Ilagan R, Zhan LJ, Pottratz J, et al. Imaging androgen receptor function during flutamide treatment in the LAPC9 xenograft model. Mol Cancer Ther. 2005;4:1662-1669.

67. Jin YN, Chung HK, Kang JH, et al. Hepatoma-targeted human sodium iodide symporter gene expression using $\alpha$-fetoprotein enhancer/promoter [abstract]. J Nucl Med. 2007;48(suppl):328P.

68. Willhauck MH, Sharif Samani BR, Klutz K, et al. Alpha-fetoprotein promotertargeted sodium iodide symporter gene therapy of hepatocellular carcinoma. Gene Ther. 2007;15:214-223.

69. Winkeler A, Sena-Esteves M, Paulis LE, et al. Switching on the lights for gene therapy. PLoS ONE. 2007;2:e528.

70. Doubrovin M, Ponomarev V, Beresten T, et al. Imaging transcriptional regulation of p53-dependent genes with positron emission tomography in vivo. Proc Natl Acad Sci USA. 2001;98:9300-9305.

71. Kim KI, Chung JK, Kang JH, et al. Visualization of endogenous p53-mediated transcription in vivo using sodium iodide symporter. Clin Cancer Res. 2005; 11:123-128.

72. Chung HK, Chung JK, Kang JH, et al. Monitoring the activation of NF-кB signal pathway using luciferase reporter system [abstract]. J Nucl Med. 2007; 48(suppl):168P.

73. Vykhovanets EV, Shukla S, MacLennan GT, et al. Molecular imaging of NFkappaB in prostate tissue after systemic administration of IL-1 beta. Prostate. 2008;68:34-41.

74. Chan CT, Paulmurugan R, Gheysens OS, Kim J, Chiosis G, Gambhir SS. Molecular imaging of the efficacy of heat shock protein 90 inhibitors in living subjects. Cancer Res. 2008;68:216-226.

75. Kang Y, He W, Tulley S, et al. Breast cancer bone metastasis mediated by the Smad tumor suppressor pathway. Proc Natl Acad Sci USA. 2005;102:13909-13914.

76. So MK, Kang JH, Chung JK, et al. In vivo imaging of retinoic acid receptor activity using a sodium/iodide symporter and luciferase dual imaging reporter gene. Mol Imaging. 2004;3:163-171.

77. Kang JH, Chung JK, Lee YJ, et al. Evaluation of transcriptional activity of the oestrogen receptor with sodium iodide symporter as an imaging reporter gene. Nucl Med Commun. 2006;27:773-777.

78. Iyer M, Wu L, Carey M, Wang Y, Smallwood A, Gambhir SS. Two-step transcriptional amplification as a method for imaging reporter gene expression using weak promoters. Proc Natl Acad Sci USA. 2001;98:14595-14600.

79. Massoud TF, Paulmurugan R, Ed A, Ray P, Gambhir SS. Reporter gene imaging of protein-protein interactions in living subjects. Curr Opin Biotechnol. 2007;18:31-37.

80. Luker GD, Sharma V, Pica CM, et al. Noninvasive imaging of protein-protein interactions in living animals. Proc Natl Acad Sci USA. 2002;99:6961-6966.

81. Paulmurugan R, Umezawa Y, Gambhir SS. Non-invasive imaging of proteinprotein interactions in living subjects by using reporter protein complementation and reconstitution strategies. Proc Natl Acad Sci USA. 2002;99:1560815613.

82. Zhang L, Lee KC, Bhojani MS, et al. Molecular imaging of Akt kinase activity. Nat Med. 2007;13:1114-1119.

83. Contag $\mathrm{CH}$, Ross BD. It's not just about anatomy: in vivo bioluminescence imaging as an eyepiece into biology. J Magn Reson Imaging. 2002;16:378-387.

84. Shin JH, Chung JK, Kang JH, et al. Noninvasive imaging for monitoring of viable cancer cells using dual-imaging reporter gene. J Nucl Med. 2004;45: 2109-2115.

85. Kim HJ, Jeon $\mathrm{YH}$, Kang $\mathrm{JH}$, et al. In vivo long-term imaging and radioiodine therapy by sodium iodide symporter gene expression using a lentiviral system containing ubiquitin C promoter. Cancer Biol Ther. 2007;6:1130-1135.

86. Nakajima A, Seroogy CM, Sandora MR, et al. Antigen-specific T cell-mediated gene therapy in collagen-induced arthritis. J Clin Invest. 2001;107:1293-1301.

87. Costa GL, Sandora MR, Nakajima A, et al. Adoptive immunotherapy of experimental autoimmune encephalomyelitis via T cell delivery of the IL-12 p40 subunit. J Immunol. 2001;167:2379-2387.

88. Serganova I, Blasberg R. Reporter gene imaging: potential impact on therapy. Nucl Med Biol. 2005;32:763-780.

89. Koehne G, Doubrovin M, Doubrovina E, et al. Serial in vivo imaging of the targeted migration of human HSV-TK-transduced antigen-specific lymphocytes. Nat Biotechnol. 2003;21:405-413. 
90. Ponomarev R, Doubrovin M, Lyddane C, Beresten T, Balatoni JG. Imaging TCR-dependent NFAT-mediated T-cell activation with positron emission tomography in vivo. Neoplasia. 2001;3:480-488.

91. Acton PD, Zhou R. Imaging reporter genes for cell tracking with PET and SPECT. Q J Nucl Med Mol Imaging. 2005;49:349-360.

92. Wu JC, Chen IY, Sundaresan G, et al. Molecular imaging of cardiac cell transplantation in living animals using optical bioluminescence and positron emission tomography. Circulation. 2003;108:1302-1305.

93. Shin JH, Chung JK, Roh JK, et al. Monitoring of neural stem cell using sodium/ iodide symporter gene [abstract]. J Nucl Med. 2002;43(suppl):238P.

94. Hwang DW, Kang JH, Jeong JM, et al. Noninvasive in vivo monitoring of neuronal differentiation using reporter driven by a neuronal promoter. Eur $J$ Nucl Med Mol Imaging. 2008;35:135-145.

95. Kim KI, Kang JH, Chung JK, et al. Doxorubicin enhances the expression of transgene under control of the CMV promoter in anaplastic thyroid carcinoma cells. J Nucl Med. 2007;48:1553-1561.

96. Minn AJ, Kang Y, Serganova I, et al. Distinct organ-specific metastatic potential of individual breast cancer cells and primary tumors. J Clin Invest. 2005; 115:44-55.

97. Lyons SK, Lim E, Clermont AO, et al. Noninvasive bioluminescence imaging of normal and spontaneously transformed prostate tissue in mice. Cancer Res. 2006;66:4701-4707.

98. Jeon YH, Choi Y, Kim HJ, et al. Human sodium iodide symporter gene adjunctive radiotherapy to enhance the preventive effect of hMUC1 DNA vaccine. Int J Cancer. 2007;121:1593-1599.

99. Jeon YH, Choi Y, Kim HJ, et al. In vivo bioluminescence visualization of antitumor effects by human MUC1 vaccination. Mol Imaging. 2007;6:297-303.

100. Sweeney TJ, Mailander V, Tucker AA, et al. Visualizing the kinetics of tumorcell clearance in living animals. Proc Natl Acad Sci USA. 1999;96:1204412049.

101. Vooijs M, Jonkers J, Lyons S, Berns A. Noninvasive imaging of spontaneous retinoblastoma pathway-dependent tumors in mice. Cancer Res. 2002;62:18621867.

102. Maggi A, Ottobrini L, Biserni A, Lucignani G, Ciana P. Techniques: reporter mice-a new way to look at drug action. Trends Pharmacol Sci. 2004;25:337-342.
103. Gossen JA, de Leeuw WJ, Tan CH, et al. Efficient rescue of integrated shuttle vectors from transgenic mice: a model for studying mutations in vivo. Nat Biotechnol. 1989;86:7971-7975.

104. Sacco MG, Zecca L, Bagnasco L, et al. A transgenic mouse model for the detection of cellular stress induced by toxic inorganic compounds. Nat Biotechnol. 1997;15:1392-1397.

105. Wirth D, Christians E, Munaut C, et al. Differential heat shock gene hsp70-1 response to toxicants revealed by in vivo study of lungs in transgenic mice. Cell Stress Chaperones. 2002;7:387-395.

106. Zhang W, Puchia AF, Chen K, et al. A transgenic mouse model with a luciferase reporter for studying in vivo transcriptional regulation of the human CYP3A4 gene. Drug Metab Dispos. 2003;31:1054-1064.

107. Iyer M, Salazar FB, Lewis X, et al. Non-invasive imaging of a transgenic mouse model using a prostate-specific two-step transcriptional amplification strategy. Transgenic Res. 2005;14:47-55.

108. Cao YA, Wagers AJ, Beilhack A, et al. Shifting foci of hematopoiesis during reconstitution from single stem cells. Proc Natl Acad Sci USA. 2004;101:221-226.

109. Kang JH, Lee DS, Paeng JC, et al. Development of a sodium/iodide symporter (NIS)-transgenic mouse for imaging of cardiomyocyte-specific reporter gene expression. J Nucl Med. 2005;46:479-483.

110. Saito Y, Price RW, Rottenberg DA, et al. Quantitative autoradiographic mapping of herpes simplex virus encephalitis with a radiolabeled antiviral drug. Science. 1982;217:1151-1153.

111. Jacobs A, Tjuvajev JG, Dubrovin M, et al. Positron emission tomography-based imaging of transgene expression mediated by replication-conditional, oncolytic herpes simplex virus type 1 mutant vectors in vivo. Cancer Res. 2001;61:2983-2995.

112. Bennett JJ, Tjuvajev J, Johnson P, et al. Positron emission tomography imaging for herpes virus infection: implications for oncolytic viral treatments of cancer. Nat Med. 2001;7:859-863.

113. Kadurugamuwa JL, Sin LV, Yu J, et al. Rapid direct method for monitoring antibiotics in a mouse model of bacterial biofilm infection. Antimicrob Agents Chemother. 2003;47:3130-3137.

114. Min JJ, Kim HJ, Park JH, et al. Noninvasive real-time imaging of tumors and metastases using tumor-targeting light-emitting Escherichia coli. Mol Imaging Biol. 2007;10:54-61. 